$$
\begin{gathered}
\text { UNIVERSIDADE DE SÃO PAULO } \\
\text { FACULDADE DE ODONTOLOGIA DE RIBEIRÃO PRETO }
\end{gathered}
$$

Sônia Maria Lemos Brancato Camarinha

\begin{abstract}
AVALIAÇÃO DA ADAPTAÇÃO DE NÚCLEO METÁLICO FUNDIDO EM FUNÇÃO DA TÉCNICA DE MOLDAGEM
\end{abstract}

Ribeirão Preto 
Sônia Maria Lemos Brancato Camarinha

\section{AVALIAÇÃO DA ADAPTAÇÃO DE NÚCLEO METÁLICO FUNDIDO EM FUNÇÃO DA TÉCNICA DE MOLDAGEM}

Dissertação apresentada à Faculdade de Odontologia de Ribeirão Preto, da Universidade de São Paulo, para obtenção do título de Mestre em Odontologia

Área de concentração: Reabilitação Oral

Orientadora: Profa. Dra. Fernanda de Carvalho Panzeri Pires de Souza

Ribeirão Preto

2008 
AUTORIZO A REPRODUÇÃO E DIVULGAÇÃO TOTAL OU PARCIAL DESTE TRABALHO, POR QUALQUER MEIO CONVENCIONAL OU ELETRÔNICO PARA FINS DE ESTUDO E PESQUISA, DESDE QUE CITADA A FONTE

Camarinha, Sônia Maria Lemos Brancato

Avaliação da adaptação de núcleo metálico fundido em função da técnica de moldagem. Ribeirão Preto, 2008.

71 p. : il. ; $30 \mathrm{~cm}$

Dissertação de Mestrado, apresentada à Faculdade de Odontologia de Ribeirão Preto/USP. Área de concentração: Reabilitação Oral.

Orientador: Pires-de-Souza, Fernanda de Carvalho Panzeri.

1. Núcleo Metálico Fundido. 2. Silicona polimerizada por adição.

3. Silicona polimerizada por condensação. 4. Moldagem. 


\section{FOLHA DE APROVAÇÃO}

CAMARINHA, S. M. L. B. Avaliação da adaptação de núcleo metálico fundido em função da técnica de moldagem. Dissertação (Mestrado em Reabilitação Oral). Faculdade de Odontologia de Ribeirão Preto, Universidade de São Paulo.

\section{Banca Examinadora}

Aprovado em:

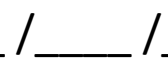

1) $\operatorname{Prof}(a) \cdot \operatorname{Dr}(a)$

Instituição:

Assinatura:

2) $\operatorname{Prof}(a) \cdot \operatorname{Dr}(a) \cdot$ :

Instituição:

Assinatura:

3) $\operatorname{Prof}(a) \cdot \operatorname{Dr}(a) .:$

Instituição: Assinatura: 


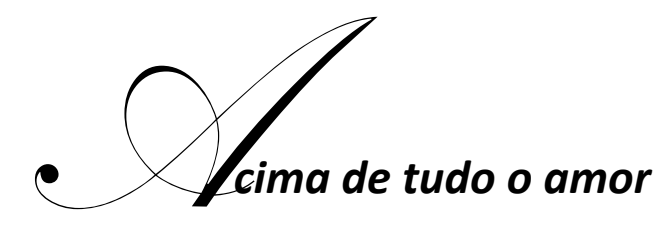

Ainda que eu falasse a língua dos homens e dos anjos, Se eu não tivesse o amor, seria como um sino ruidoso Ainda que eu tivesse o dom da profecia, o conhecimento de todos os mistérios e de toda ciência; ainda que eu tivesse toda fé, a ponto de transpor montanhas, se eu não tivesse o amor, eu não seria nada...

O amor é paciente, o amor é prestativo;

Não é invejoso, não se ostenta, não se incha de orgulho. Nada faz de inconveniente, não procura seu próprio interesse, não se irrita, não guarda rancor.

Não se alegra com a injustiça, mas se regozija com a verdade.

Tudo desculpa, tudo crê, Tudo espera, tudo suporta.

$$
\text { amor jamais passará. }
$$

(1Coríntios 13,1-8) 


\section{Dedico este trabalho:}

\section{A Deus,}

pelo dom da vida, pela constante presença, por guiar e orientar todos os meus passos segundo seus ensinamentos. Ele que é ciência plena e como tal, nos permite aproximação através da busca do conhecimento. Obrigado meu Deus, por suas bênçãos e por me fazer cada dia uma pessoa melhor.

\section{Aos meus pais José Luiz e Eliete,}

por estarem sempre presente em minha vida, sempre seguirei me espelhando em vocês, meus ídolos, amigos e incentivadores, muitas vezes abdicando dos seus sonhos para que os meus fossem realizados. Vocês são exemplos de caráter, perseverança e amor incondicional. Amo muito vocês.

\section{A João Carlos meu amado marido,}

e colega, que soube tão bem compreender o significado deste trabalho para minha realização pessoal e profissional, me dando a cooperação, serenidade necessária e o estímulo para a concretização deste ideal. Obrigada por estar sempre ao meu lado, o seu apoio foi fundamental para que eu chegasse até aqui. Meu eterno amor a você.

\section{Aos meus filhos Vanessa, Mariana e Alexandre,}

razão do meu viver, obrigado meus amores por terem compreendido o significado deste trabalho e por me ajudarem a superar os obstáculos e continuar lutando. Perdão pelos momentos ausentes, mas saibam que em todos os momentos vocês estão no meu coração. 


\section{As minhas queridas irmãs Ana e Márcia,}

que tanto me apoiaram, e compartilharam de momentos maravilhosos de alegria e companheirismo, obrigada pela ajuda e colaboração para que eu pudesse concluir esta etapa de minha vida. Amo vocês.

Aos meus sogros Cid (in memorian) e Teresinha,

que sempre acreditaram em mim e me incentivaram para que eu seguisse em frente na vida profissional e realização pessoal. 0 meu eterno agradecimento, pelo apoio e suporte. Com todo meu amor e carinho.

Aos meus cunhados Luís Antonio, Paulo Sérgio (in memorian), Cidinho e Suzana; e sobrinhos Juliana, Daniel, Nathália, Cid e Rodrigo

obrigada pela presença constante, pelo apoio, incentivo e valiosa colaboração. Nath, obrigada pela máquina fotográfica. Amo vocês

\section{A todos os meus familiares,}

tios e primos, pelo amor e carinho durante toda a minha vida e na realização deste e de outros projetos, vocês estão dentro do meu coração. 


\section{Agradecimentos Especiais}

A Prof ${ }^{a}$. Dr ${ }^{a}$. Fernanda de Carvalho Panzeri Pires de Souza, foi através do amor de Deus que nos conhecemos, e é por esse amor que a nossa amizade se tornou tão forte e bonita. Obrigada por me passar sua experiência, e conhecimento e compartilhar de momentos tão maravilhosos na pesquisa. O seu profissionalismo e dedicação me fizeram acreditar, ainda mais, que realmente vale a pena lutar pelo nosso ideal e por esta profissão tão linda que escolhemos. Os nossos momentos de reflexão aumentaram ainda mais a minha admiração por você, pessoa verdadeira por quem eu tenho um carinho muito especial e eterno agradecimento.

Prof. Dr. Luiz Carlos Pardini, as palavras são poucas para expressar a imensa gratidão por você, a sua humildade e disposição em poder compartilhar um pouco da sua imensa sabedoria foi algo especial para mim. A você por quem tenho profunda admiração, meu sincero e carinhoso agradecimento. 


\section{Agradecimentos}

À Faculdade de Odontologia de Ribeirão Preto, da Universidade de São Paulo, seus professores e funcionários, pela oportunidade de conhecimento na área da pesquisa, e pelas novas amizades.

Ao Prof. Dr. Heitor Panzeri, pela sua incansável dedicação ao ensino e humildade em compartilhar conosco toda sua sabedoria.

Ao Prof. Dr. Osvaldo Luiz Bezzon, chefe do departamento e coordenador da pós-graduação, pelo seu excelente desempenho em levar nosso curso de pós-graduação ao nível de excelência que hoje se encontra.

A Profa. Dra. Helena de Oliveira Paranhos, com sua delicadeza nos ensinou o verdadeiro significado da nossa profissão.

A Profa. Dra. Alma Blasida C. E. B. Cartise, professora com inúmeras qualidades, fez nos enxergar o nosso interior com suas aulas de expressão corporal.

Aos Profs. Drs. Iara, Claudia, Rossana, Zaniquelli, Ricardo, Maria da Glória, Rafael, Valéria, Renata, Marco Antonio, o meu eterno agradecimento por ter compartilhado de momentos maravilhosos junto a vocês e pela contribuição à minha formação na pós graduação.

As minhas queridas amigas de pós-graduação Ana Maria, Rosaly e Sandra, pela nossa amizade. Recebam meu carinho e admiração por vocês, espero estarmos sempre juntas. 
A todos os meus colegas e amigos da turma de mestrado: Patrícia, Toni, Pâmela, Fabiano, Ingrid, Fabrício, Janisse, Abílio, Alessandra, Letícia, Diogo, Jeovan, Lâner, Hisham, Cristiano, Marco, Ana Luiza, Edmilson, Humberto, Natércia e Amanda. É muito bom tê-los como amigos, desejo a todos vocês muito sucesso.

Ao funcionário Francisco Lourenço Roselino, obrigada por todo apoio e suporte que você me deu nos meses em que estive no laboratório, a sua ajuda foi de grande valia para o êxito deste projeto.

Aos funcionários Paulo, Godoy, Ana Paula Macedo, Hermano e todos os técnicos do laboratório pela disponibilidade, suporte técnico e auxílio na conclusão deste projeto.

Às secretárias da pós-graduação Regiane Tirado, Ana Paula Xavier, Izabel Sola, Regiane Sacilotto, pela atenção dispensada a mim, o meu muito obrigado.

Aos meus colegas e amigos Cap Dent PM José Roberto de Freitas e 10 Ten Dent PM José Mário Cano, pela valiosa colaboração e companheirismo, por estarem sempre me apoiando e me incentivando.

Ao meu colega 10 Ten Dent PM Cácio Bighetti de Oliveira, primeiro autor desta técnica, desejo a você muito sucesso, e espero que este trabalho perpetue o que você iniciou.

Ao Ten Cel Dent Res PM Dionísio Vinha, pelo exemplo de dedicação ao ensino, apoio e colaboração. 
Aos Comandantes Ten Cel Res PM Ênio Antonio de Moraes e Ten Cel PM Lúcio Teófilo Pacheco, Sub Comandante Maj PM Frank de Andrade, Oficiais e Praças do 9o Grupamento de Bombeiros, por acreditarem na minha capacidade profissional e me apoiarem para que pudesse concluir com êxito este projeto.

Aos Comandantes do $\mathrm{CPI} / 3$ Cel Res PM João Roberto do Nascimento e Ten Cel PM Ari Roberto Vicente da Silva e do 43BㅗM/I Ten Cel PM Fernando Luis Bragatto, Oficiais e Praças, por confiarem na minha profissão e acreditarem no meu projeto.

À Vigodent S/A Indústria e Comércio, pelo fornecimento dos materiais odontológicos e pela confiança na realização de uma parceria de sucesso.

A Associação de Fundo de Auxílio Mutuo da Polícia Militar do Estado de São Paulo (AFAM), por ter selecionado meu projeto e pelo apoio financeiro.

Ao querido amigo Padre Pitico, obrigada pelo incentivo e orações, o seu trabalho espiritual e a sua disposição é um exemplo de vida para nós. Você é uma pessoa muito especial.

Aos queridos amigos das ENS e ECC, o meu eterno agradecimento pelas orações dedicadas a mim para a realização deste trabalho.

A todos meus amigos, amigas e pacientes o meu sincero carinho, agradecimento e compreensão pelos momentos de ausência durante a execução deste trabalho.

A todos que direta ou indiretamente colaboraram para a realização deste trabalho. 
CAMARINHA, S. M. L. B. Avaliação da adaptação de núcleo metálico fundido em função da técnica de moldagem. Ribeirão Preto, 2008. 71p. Dissertação (Mestrado em Reabilitação Oral). Faculdade de Odontologia de Ribeirão Preto, Universidade de São Paulo.

\section{RESUMO}

O núcleo metálico fundido (NMF), dentre outras funções, visa suportar a restauração que o sobrepõe. Muitas são as técnicas que podem ser utilizadas para a obtenção deste núcleo; o importante, porém, para manutenção da integridade dental, é a sua perfeita adaptação intra-radicular. Este trabalho apresenta um método para moldagem de condutos radiculares utilizando, como suporte intra-radicular, agulha hipodérmica. Foram realizados tratamentos endodônticos em 10 dentes humanos uniradiculares e, após o preparo, o conduto foi moldado (dupla impressão) com siliconas polimerizadas por condensação e adição, pela técnica indireta, utilizando dois tipos de suporte intra-radicular (pinjet e agulha hipodérmica). Foram obtidos 4 moldes de cada dente (interagindo material $x$ técnica) totalizando 40 modelos, sobre os quais foram encerados os núcleos. Após a fundição, a adaptação dos núcleos foi analisada segundo dois métodos: radiográfico e microscópico. No primeiro, os dentes foram radiografados com os NMFs em posição e as imagens digitalizadas foram analisadas em computador (software ImageLab). Para avaliação microscópica, os dentes foram seccionados longitudinalmente, os núcleos foram adaptados no interior do canal e a adaptação foi verificada em microscópio de dupla coordenada, em que era calculada a porcentagem do conduto ocupada pelo NMF. Constatou-se que houve diferença estatisticamente significante ( 2 way ANOVA - Bonferroni $-p<0.05$ ) entre as médias dos valores de adaptação obtidos em função da técnica (agulha $x$ pinjet) utilizando a silicona polimerizada por adição, nos dois métodos de avaliação. Não houve diferença estatisticamente significante em relação aos materiais de moldagem utilizados. Concluiu-se que a técnica utilizando agulha hipodérmica apresentou melhor fidelidade de reprodução permitindo melhor adaptação do NMF, quando utilizada a silicona polimerizada por adição.

Palavras Chaves: NMF, silicona polimerizada por adição, silicona polimerizada por condensação, moldagem. 
CAMARINHA, S. M. L. B. Evaluation of post and core adaptation concerning the molding technique. Ribeirão Preto, 2008. 71p. Dissertação (Mestrado em Reabilitação Oral). Faculdade de Odontologia de Ribeirão Preto, Universidade de São Paulo.

\section{ABSTRACT}

Post and core aim to support the crown, being necessary a perfect intraradicular adaptation. There are several techniques that can be used to obtain cores, however, in order to maintain dental integrity, it is important to achieve a perfect intra-radicular adaptation. This study presents an inedited and innovator method for molding root canals using hypodermic needle as intra-radicular support. Endodontic treatment was done in 10 uniradicular human teeth and, after the preparation, root canals were molded (double print) with condensation cure silicone and addition cure silicone by indirect technique, using two types of intra-radicular supports (Pinjet and hypodermic needle). Four molds were obtained from each tooth (interacting material $X$ technique) totalizing 40 models, on which the cores were polished. After fusion, the adaptation of cores was analyzed according to two methods: radiographic and microscopic. In the first, teeth were radiographed with the core in position and the digitalized images were analyzed through ImageLab software. For microscopic evaluation, teeth were longitudinally sectioned, the cores were adapted into root canals, and the adaptation was verified in microscope of double coordinate. The occupation percentage of core into root canal was calculated. A significant statistical difference (two-way ANOVA and Bonferroni's $-p<0.05$ ) was found between mean values of adaptation considering the molding technique (needle $x$ pinjet) using the addition silicon in the two evaluated methods. There was no significant statistical difference regarding the utilized materials. It was concluded that the hypodermic needle technique had better fidelity of reproduction, permitting a good adaptation of cores, regardless of the material utilized.

Keywords: Post and core, condensation and addition silicone, molding technique 


\section{LISTA DE FIGURAS}

Figura 01 Silicona polimerizada por adição......................................... 30

Figura 02 Silicona polimerizada por condensação............................... 30

Figura 03 Agulha Hipodérmica....................................................... 30

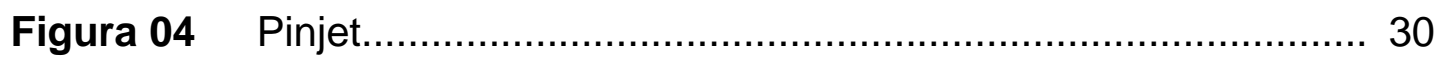

Figura 05A Posicionamento do dente para radiografia........................... 31

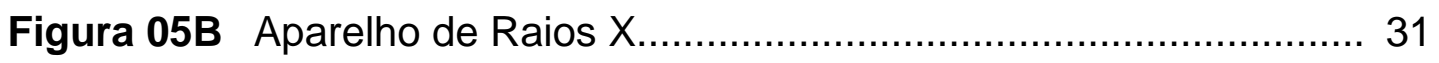

Figura 06A Posicionamento do cone de Raios X................................ 32

Figura 06B Posicionamento do dente, penetrômetro de identificação na película........................................................................... 32

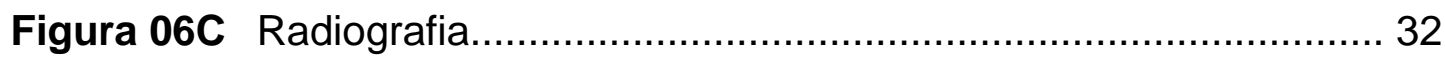

Figura 07 Radiografia após tratamento endodôntico................................ 33

Figura 08 Radiografia do preparo do conduto radicular......................... 34

Figura 09A Delineador com peso de 380 gramas na parte superior, moldeira e base de resina na parte inferior........................... 35

Figura 09B Dente posicionado e stops de resina acrílica......................... 35

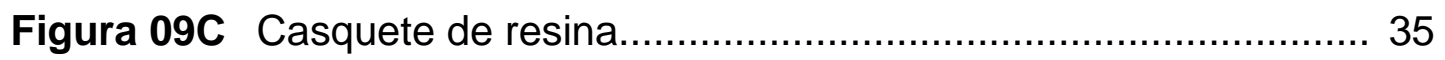

Figura 10A Seqüência de moldagem: posicionamento do casquete de

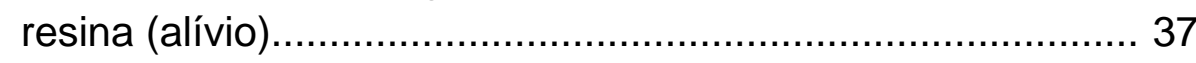

Figura 10B Moldagem com material de alta viscosidade...................... 37

Figura 10C Casquete de resina (alívio) no molde................................... 37

Figura 10D Remoção do casquete de resina (alívio) do

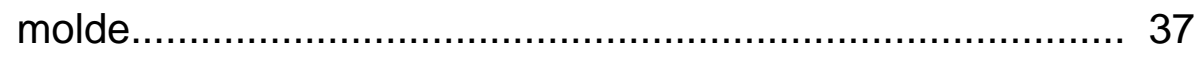

Figura 10E Posicionamento do suporte intra-radicular (agulha

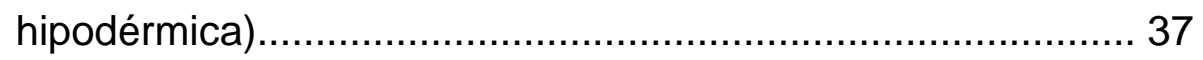

Figura 10F Posicionamento do suporte intra-radicular (pinjet)................. 37

Figura 10G Moldagem com material de baixa viscosidade ......................... 37

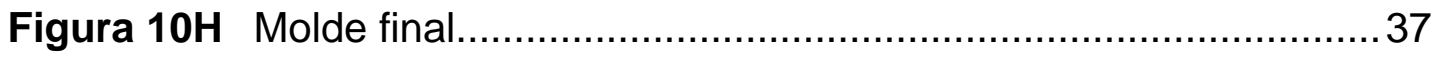




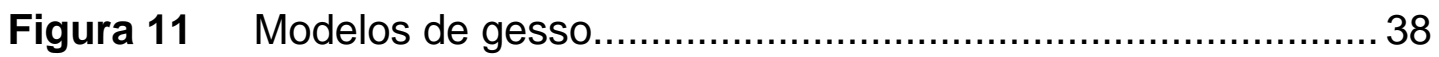

Figura 12 Escultura dos núcleos em duralay....................................... 39

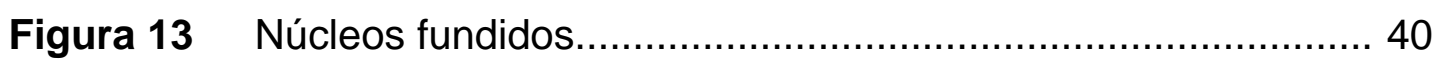

Figura 14A Leitura da radiografia no Programa Image Lab comprimento do conduto.................................................... 41

Figura 14B Leitura da radiografia no Programa Image Lab comprimento do núcleo........................................................ 41

Figura 15 Comprimento do conduto com os NMFs adaptados a partir da técnica de moldagem feita com: $1 \mathrm{~A}$ - silicona polimerizada por adição e agulha hipodérmica; 1B- silicona polimerizada por adição e pinjet; 1C- silicona polimerizada por condensação e agulha hipodérmica; 1D silicona polimerizada por condensação e pinjet.

Figura 16 Comprimento do NMF adaptados a partir da técnica de moldagem feita com: 1A- silicona polimerizada por adição e agulha hipodérmica; 1B- silicona polimerizada por adição e pinjet; 1C- silicona polimerizada por condensação e agulha hipodérmica; 1D silicona polimerizada por condensação e pinjet

Figura 17 Inclusão do dente na resina acrílica...................................... 42

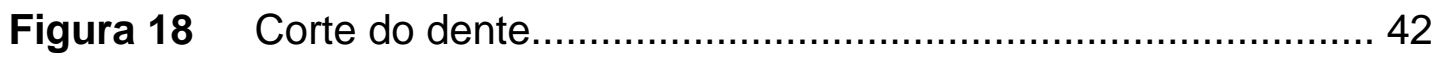

Figura 19 Aparelho SYJ-150 Digital Low Speed Diamond Saw.......... 42

Figura 20 Adaptação do NMF feito a partir da técnica de moldagem com: 1A- silicona polimerizada por adição e agulha hipodérmica; 1B- silicona polimerizada por adição e pinjet; 1C- silicona polimerizada por condensação e agulha hipodérmica; 1D silicona polimerizada por condensação e pinjet.

Figura 21 Microscópio de dupla coordenada.......................................... 43

Figura 22 Medida do conduto radicular da cervical até o final do preparo

Figura 23 Medida da distância entre o final do núcleo ao início da obturação. 
Figura 24 Comparação das médias entre as técnicas de moldagem feitas com silicona polimerizada por adição e condensação utilizando agulha hipodérmica e pinjet a partir das leituras das imagens radiográficas.

Figura 25 Comparação das médias entre as técnicas de moldagem feitas com silicona polimerizada por adição e condensação utilizando agulha hipodérmica e pinjet a partir das leituras feitas em microscópio.......................................................... 50 


\section{LISTA DE TABELAS}

Tabela 01 Comprimento dos dentes...................................... 34

Tabela 02 Sequencia dos grupos experimentais......................... 38

Tabela 03 Comprimento do conduto, núcleo e porcentagem da extensão do canal que o núcleo ocupa........................... 42

Tabela 04 Porcentagem de preenchimento dos condutos radiculares pelos NMFs e suas médias e respectivos desvios-padrão, após análise radiográfica

Tabela 05 Análise estatística dos dados (2-way ANOVA, Bonferroni, nível de significância de 95\%) após análise radiográfica.................................................................... 47

Tabela 06 Porcentagem de preenchimento dos condutos radiculares pelos NMFs e suas médias e respectivos desvios-padrão, após análise microscópica.................................................. 49

Tabela 07 Análise estatística dos dados (2-way ANOVA, Bonferroni, nível de significância de 95\%) após análise microscópica..... 49

Tabela 08 Análise radiográfica: medidas dos condutos radiculares, extensão do núcleo dentro do canal e a respectiva porcentagem representativa de sua ocupação, em relação ao comprimento do canal.

Tabela 09 Análise microscópica: medidas dos condutos radiculares.......68

Tabela 10 Análise microscópica: medidas da extensão do núcleo dentro do canal e a respectiva porcentagem representativa de sua ocupação, em relação ao comprimento do canal 


\section{SUMÁRIO}

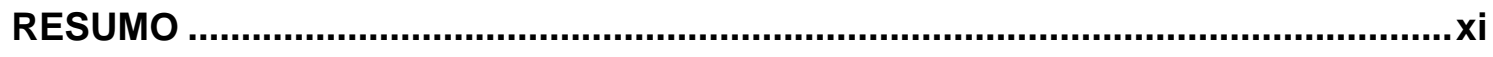

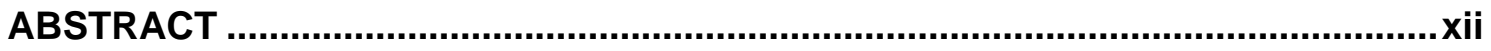

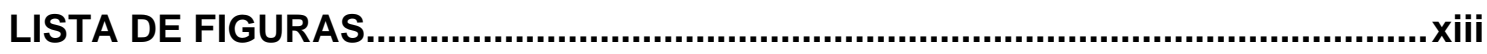

LISTA DE TABELAS .............................................................................................

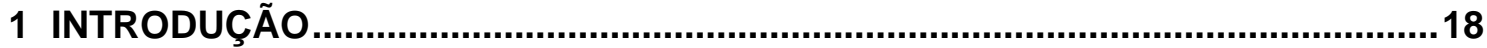

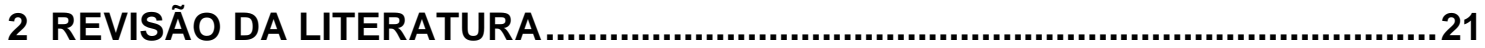

3 PROPOSIÇÃO

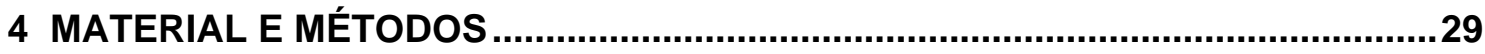

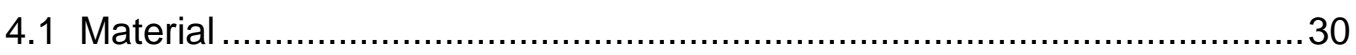

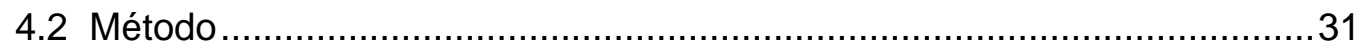

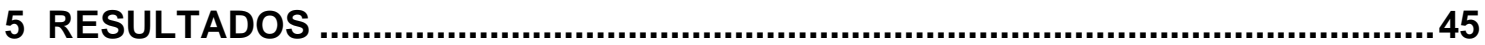

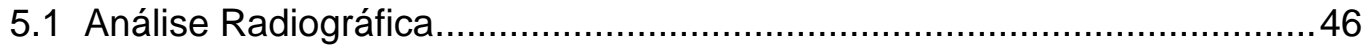

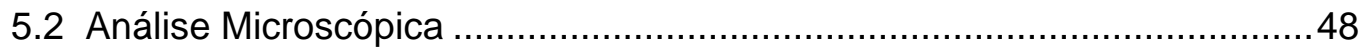

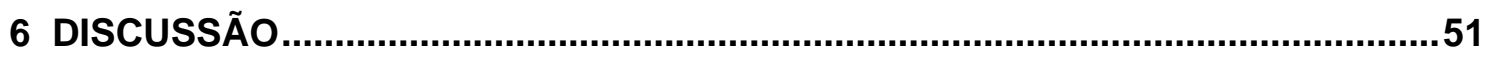

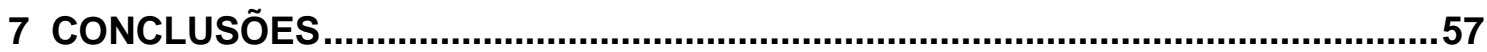

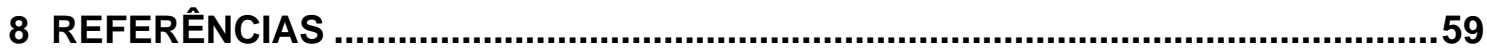

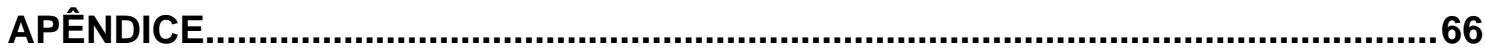

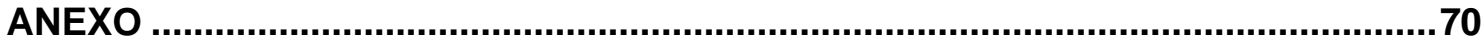


1. INTRODUÇÃO 


\section{INTRODUÇÃO}

Os dentes tratados endodonticamente normalmente são mais frágeis, devido à perda de estrutura dental causada por cáries, preparos cavitários, instrumentação do canal radicular e diminuição da umidade dentinária (HELFER et al, 1972) que resulta na alteração do dente, tornando-o mais susceptível à fraturas. Várias modificações ocorrem no dente após o tratamento endodôntico dificultando a forma de restaurá-lo; portanto o correto planejamento e o tipo de restauração a ser empregada tornam-se imprescindíveis para o sucesso da reconstrução dentária.

Para restaurar um dente com tratamento endodôntico devemos devolver a forma e função criando recursos para ancorar a restauração, evitando o seu descolamento e otimizando a distribuição das forças recebidas, evitando a concentração de cargas, dissipando-a pelo periodonto, prevenindo assim, a fratura do remanescente dental que estará sob o efeito de forças funcionais e parafuncionais exercidas sobre o dente (SILVERSTEIN, 1964). Umas das alternativas para essa recuperação é através da confecção de um núcleo metálico fundido (NMF), tornando o dente mais resistente, servindo de suporte para uma futura prótese dentária.

O NMF possui uma porção intra-radicular que é fixada no conduto previamente preparado, e uma porção externa coronária, substituindo o dente preparado para receber uma coroa dental. Podem ser obtidos em metais nobres, não nobres ou semi-nobres, a partir de padrões de resina acrílica ou de cera confeccionados diretamente na boca do paciente, ou indiretamente em modelos de gesso dos condutos radiculares preparados (SHILLINGBURG e 
KESSLER, 1991). Segundo essa técnica, o processo mais rotineiramente empregado para a confecção do NMF se inicia a partir da obtenção de um molde do conduto preparado com um material de moldagem elastomérico. Todos os outros passos operatórios que sucedem a moldagem na obtenção do NMF têm seu sucesso vinculado à obtenção de um molde preciso (SAITO et al, 1998; ROSENSTIEL et al., 1995).

A perfeita adaptação desse elemento da prótese deve ser um objetivo constantemente observado já que se constitui em fator fundamental para o correto comportamento retentivo e biomecânico da prótese fixa. Entretanto, não raramente observamos problemas de ordem funcional decorrentes da má adaptação do NMF, levando, muitas vezes, ao insucesso da prótese ou, em casos mais graves, a fratura da raiz. Em geral, tais situações decorrem do efeito cumulativo de fatores envolvidos tanto em procedimentos clínicos (preparo, moldagem, armazenamento do molde e obtenção do modelo) quanto laboratoriais (escultura, fundição e acabamento) durante a execução da prótese. Dessa forma, fatores como escolha inadequada da técnica e do material de moldagem e a própria inabilidade do profissional em executar o procedimento podem contribuir decisivamente para a falta de adaptação do NMF.

Dentre o conjunto de fatores influentes na boa precisão da moldagem e perfeita adaptação da peça protética, estão as propriedades do material elastomérico e a técnica utilizada (NASR, ISKANDER, 1988). 
2. REVISÃO DA LITERATURA 


\section{REVISÃO DA LITERATURA}

Com o avanço da endodontia, ocorreram também mudanças na odontologia restauradora. Dentes que eram freqüentemente extraídos passaram a ser tratados endodonticamente. Para a restauração de dentes com tratamento endodôntico, algumas formas de tratamento podem ser indicadas, desde uma simples restauração do acesso com núcleo de preenchimento até a confecção de um NMF, dependendo da quantidade de remanescente coronário (MORGANO E BRACKETT, 1999; SMITH e SCHUMAN, 1997; CHRISTENSEN, 1996).

A confecção de núcleos metálicos fundidos (NMFs) pela técnica direta consome um tempo excessivo do profissional e paciente, porque o dentista necessita do acesso direto ao dente para o preparo e acabamento final da peça (MORTON, 1997). Muitas vezes, o acesso se torna bastante difícil dependendo da posição do dente preparado e da quantidade de núcleos a serem confeccionados. Daí a necessidade de se criar novas técnicas para minimizar o tempo de trabalho e facilitar a confecção da peça protética.

Diferentes técnicas para a confecção de um ou múltiplos NMFs tem sido descritas (SABBAK, 2002). Um requisito fundamental para uma adaptação correta do NMF é a reprodução fiel do conduto radicular para uma distribuição uniforme das forças (KRAMMER, 1996). Segundo Klooster et al (1991) uma boa moldagem requer uma reprodução exata e detalhada dos dentes e tecidos adjacentes.

Segundo Mezzomo e Frasca (1994) a moldagem dos dentes suporte e das estruturas adjacentes sobressai-se pelo seu valor estratégico, pois 
representa a passagem da situação clínica para a bancada de laboratório na forma de modelos.

A utilização de materiais adequados nas moldagens precisas, aliados a técnicas corretas, diminuem consideravelmente a possibilidade de erros (KLEINE et al., 2002) como a má adaptação dos NMFs. Tan (1995) salientou que, desde a primeira moldagem até a instalação definitiva da prótese não há como evitar a incorporação de pequenas distorções ao longo das diversas fases de elaboração da prótese. Contudo, a observação correta de técnicas eficazes e o uso de materiais de excelente qualidade permitem a execução de trabalhos com o mínimo de erros possíveis (KLEINE et al., 2002).

As siliconas surgiram na Alemanha e aos poucos foram introduzidas nos Estados Unidos. Para Phillips (1958), sua fórmula química não estava totalmente elucidada; sabia-se apenas que continha silicone em sua formulação e que sua polimerização ocorria através de grupos de hidroxila, pelo emprego de um catalisador, como o peróxido de benzoíla. Skinner (1958) afirmou que o desenvolvimento dos elastômeros foi uma das mais importantes contribuições na área odontológica.

As siliconas possuem a vantagem de serem facilmente manipuladas, não provocam manchas e não se alteram significativamente nas variações normais da temperatura ambiente (MYERS e PEYTON, 1959), porém a formação de subproduto (álcool etílico) na silicona polimerizada por reação de condensação provoca lenta e pequena contração volumétrica pela sua evaporação (BRADEN e ELLIOT, 1966). Phillips (1959), Stackhouse (1970) e Clancy et al. (1983) preconizavam o vazamento imediato dos moldes obtidos 
através das siliconas polimerizadas por condensação como forma efetiva de prevenir qualquer alteração dimensional.

São características das siliconas polimerizadas por condensação: hidrofobia, dificuldade na obtenção do modelo de gesso, simplicidade de técnica, com a utilização de moldeiras de estoque, não havendo necessidade de confecção de moldeiras individuais, boa resistência ao rasgamento, excelente recuperação elástica e ótimos resultados. Sendo utilizadas por $72 \%$ dos profissionais no Brasil (EDUARDO e MATSON, 1996).

Tjan, Wang e Miller (1981) enfatizaram a facilidade de manipulação apresentada pela silicona polimerizada por condensação e sua excelente capacidade de reprodução de detalhes. Relataram que a técnica de dupla impressão é a mais popular, uma vez que o molde inicial com a pasta pesada constitui-se numa moldeira individual que receberá a pasta leve. A pasta pesada tem grande quantidade de carga e menor alteração dimensional do que a pasta leve. Recomendaram o uso de moldeira de estoque e a adoção de espaço mínimo e uniforme para o material leve de 1,5 a 2 mm, como o objetivo de minimizar alterações.

Segundo McCabe e Wilson (1978), as siliconas polimerizadas por reação de adição são superiores aos outros materiais elastoméricos, porque sua fórmula química é diferente das siliconas convencionais, não havendo a formação de subprodutos, o que impede a contração de polimerização do material (CLANCY et al. 1983). Possui também outras características positivas, como maior tempo de trabalho, estabilidade dimensional superior, resistência à ruptura adequada, tendo um significado clínico importante, pois ocorre a ruptura do material ao invés de distorcer consideravelmente, o que poderia 
alterar o molde irreversivelmente se for submetido a tensões excessivas (YEH et al., 1980; LACY et al. 1981; MARCINAK e DRAUGHN, 1982; CHEE e DONOVAN, 1992). Uma das grandes vantagens das siliconas polimerizadas por adição é poder retardar o vazamento do molde. Williams et al. (1984) preconizavam o vazamento do gesso em 24 horas. Marcinak e Draughn (1982) acreditavam que o vazamento pode ocorrer em até sete dias ou à conveniência do profissional (CHEE e DONOVAN, 1992), mas para Craig et al. (1990) os moldes vazados após uma hora são mais precisos.

Dentre as inovações surgidas para as siliconas polimerizadas por adição há o desenvolvimento das chamadas siliconas hidrofílicas, que permitem a reprodução de detalhes de margens intra-sulculares mesmo com a presença de pequenas quantidades de fluidos (PEUTZFELDT e ASMUSSEN, 1988). Esta natureza hidrofílica é o resultado da incorporação de agentes de redução de tensão superficial, que facilitam o umedecimento da superfície (PRATTEN e CRAIG, 1989), permitindo ao gesso fluir por toda a superfície, prevenindo a inclusão de bolhas de ar, permitindo a fabricação de modelos e próteses mais exatas (CULLEN et al., 1991). Segundo Christensen (1998) quando mais da metade da coroa dental de um dente despolpado estiver destruída, é necessário o uso de um pino intra-radicular.

A confecção de NMF tem sido indicada para dentes com tratamento endodôntico e quando possuem pouca estrutura dental (SMITH, 1997 e CHRISTENSEN, 1998). Historicamente, a reconstrução da parte coronária destruída de um dente desvitalizado teve seu início por volta de 1770 com Fauchard, que usou um pino de madeira no interior do canal radicular para reter uma coroa. Com o seu umedecimento, ocorria expansão contra as 
paredes do canal radicular, aumentando a retenção do pino intra-radicular (OURIQUE, 1999). Newman et al (2003) afirmaram que a necessidade de colocação de um núcleo intra-radicular é determinada por dois fatores: a quantidade de dentina remanescente para reter o pino e a natureza interna da raiz, portanto cabe ao profissional ter conhecimentos necessários para decidir qual a melhor opção para restaurar um dente tratado endodonticamente.

A confecção de núcleos com contenção intra-radicular é um procedimento pré-protético importante para o planejamento e, principalmente, para o prognóstico de muitos casos clínicos (MANNING et al., 1995).

Para Toyooka et al. (1993) e Rubo e El-Mowafi (1998) a análise radiográfica do material se faz necessária para a avaliação da adaptação do NMF no interior do conduto e clinicamente é a técnica mais utilizada pelos profissionais.

A partir da necessidade de aprimoramento contínuo, aliada ao surgimento constante de novas categorias de materiais odontológicos, alternativas devem ser sugeridas para que os tratamentos tornem-se cada vez mais adequados às necessidades dos cirurgiões-dentistas e, principalmente, a dos pacientes. 
3. PROPOSIÇÃO 


\section{PROPOSIÇÃO}

O objetivo do presente estudo foi avaliar, radiográfica e microscopicamente, a adaptação de NMFs obtidos a partir de moldes com duas siliconas (polimerizadas por adição e por condensação) usando dois tipos de suportes intra-radiculares (pinos de policarbonato - pinjet - e agulha hipodérmica). 
4. MATERIAL E MÉTODOS 


\section{MATERIAL E MÉTODOS}

\subsection{Material}

Para o desenvolvimento desse estudo foram utilizados dois materiais para a moldagem do conduto radicular, segundo a técnica a ser avaliada: silicona polimerizada por adição (Adsil, Vigodent S/A Indústria e Comércio, Rio de Janeiro, Rio de Janeiro, Brasil - Figura 01), e silicona polimerizada por condensação (Speedex, Vigodent S/A Indústria e Comércio, Rio de Janeiro, Rio de Janeiro, Brasil - Figura 02). As técnicas testadas utilizaram, como suporte intra-radicular, dois acessórios: agulhas hipodérmicas no tamanho 0,70 X 30 milímetros (Figura 03) e pinos para moldagem intra-radicular (Figura 04) a base de policarbonato da marca pin-jet (Ângelus Indústria de Produtos Odontológicos Ltda, Londrina, PR, Brasil).

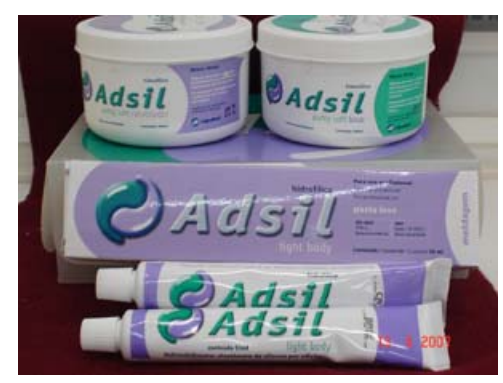

Figura 01: Silicona polimerizada por adição

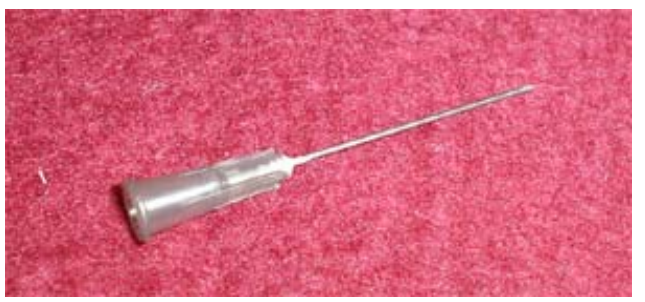

Figura 03: Agulha Hipodérmica

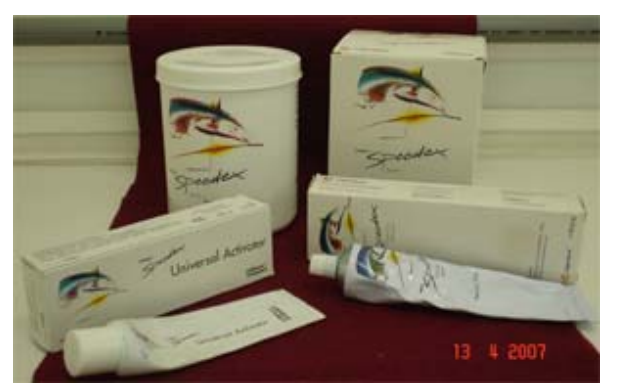

Figura 02: Silicona polimerizada por condensação

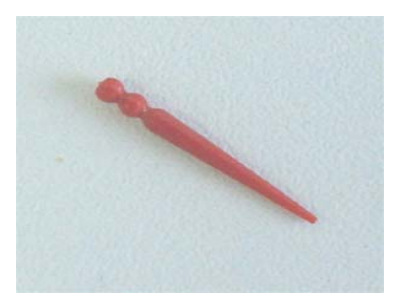

Figura 04: Pinjet 


\subsection{Método}

Após a aprovação do Comitê de Ética em Pesquisa da Faculdade de Odontologia de Ribeirão Preto da Universidade de São Paulo (Processo $\mathrm{n}^{\circ}$ 2005.1.1204.58.7), foram selecionados 10 dentes humanos unirradiculares. Estes foram radiografados utilizando-se filme da marca Kodak Insight super poly soft - Paquete, formato periapical, tamanho 2, medindo 31X41mm, IP vinte e um sensibilidade F, velocidade do filme E, com aparelhos de Raios X da marca Siemens, modelo Heliodent 60B $®$, número 0863670 D100B, série 00636 S23, voltagem de $127 \mathrm{~V}$, kilovoltagem de $60 \mathrm{Kv}$, miliamperagem de $10^{\mathrm{a}}, 50-$ $60 \mathrm{~Hz}$, filtragem inerente $0,5 \mathrm{~mm}$ de Alumínio (Al), filtragem total $2 \mathrm{~mm}$ Al (figuras 05A e B).
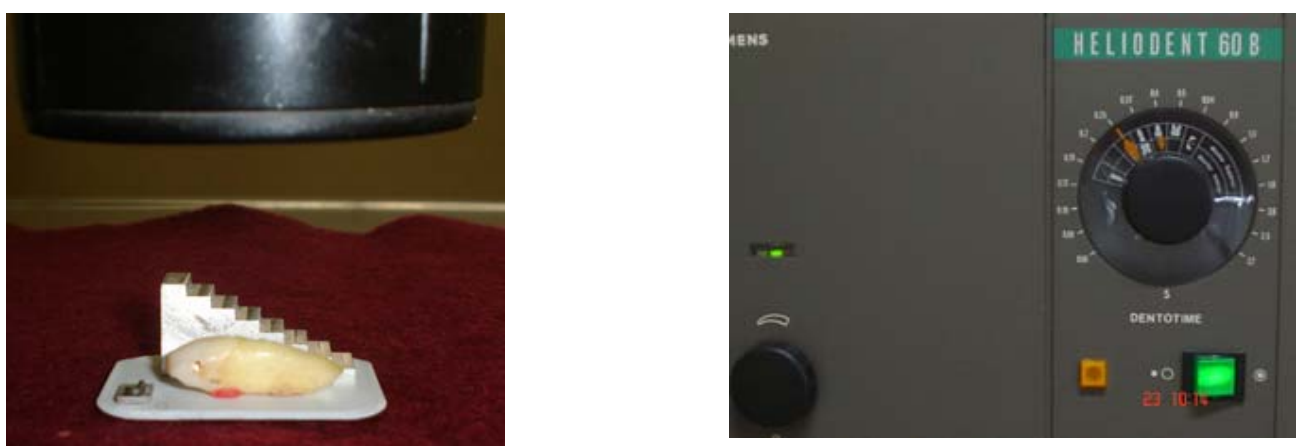

Figura 05: A - posicionamento do dente para radiografia; $\mathbf{B}$ - aparelho de raios $X$

A técnica empregada, para todas as tomadas radiográficas, foi da bissetriz, distância foco-filme (dff) igual a $18 \mathrm{~cm}$, cone curto. Todos os filmes foram identificados com letras e números de chumbo (Konex, São Paulo, SP, Brasil) e junto ao dente também foi utilizada uma escala de alumínio (penetrômetro), medindo $10 \times 32 \mathrm{~mm}$ escalonada em oito degraus com espessuras incrementais variando de 2 a $16 \mathrm{~mm}$, com o objetivo de simular, pelas nuances de tonalidades produzidas após a exposição e o processamento 
das radiografias, as densidades das estruturas da cavidade bucal em relação aos tecidos duros e mole, para a análise laboratorial da qualidade da imagem radiográfica e constar a homogeneidade dos procedimentos, além de detectar as possíveis variações durante os procedimentos das técnicas radiográficas e processamento. (figuras $06 \mathrm{~A}, \mathrm{~B}$ e C).
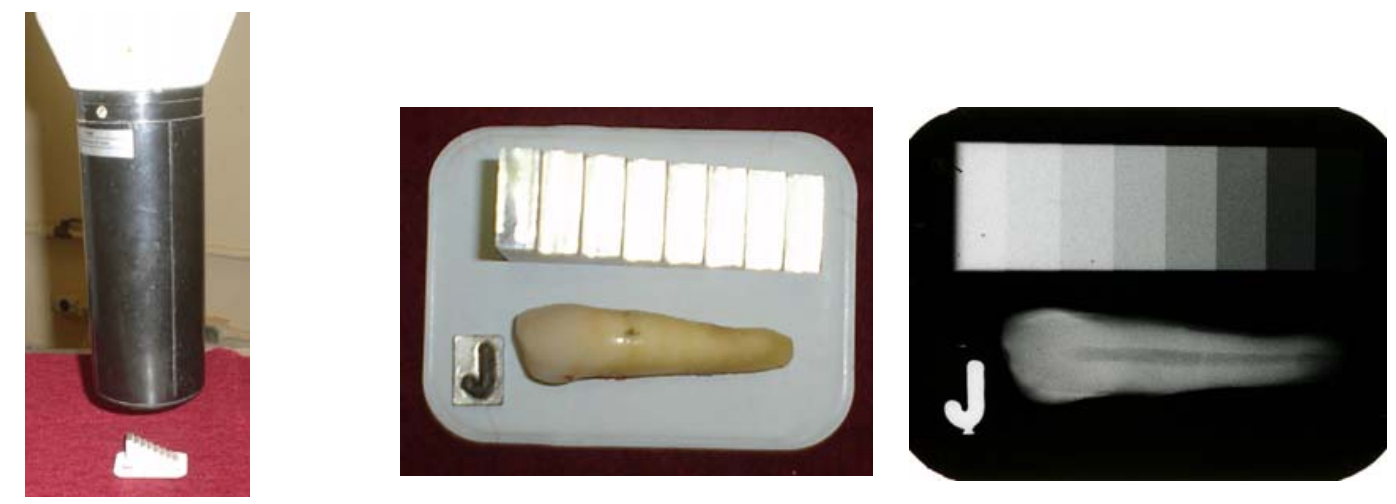

Figura 06: A - posicionamento do cone de raios X; $\mathbf{B}$ - posicionamento do dente, penetrômetro de identificação na película; $\mathbf{C}$ - radiografia

Em seguida, esses dentes tiveram suas coroas cortadas com disco de carburundum (DCL, Campinas, SP, Brasil) e micromotor (Dabi Atlante, Ribeirão Preto, SP, Brasil) e o tratamento endodôntico do canal radicular foi realizado segundo a técnica de instrumentação step-back, utilizando as limas do tipo K, da marca Maillefer (Dentsply Indústria e Comércio Ltda., Petrópolis, RJ, Brasil).

A instrumentação dos canais radiculares foi efetuada em todo o comprimento de trabalho com a utilização de quatro instrumentos, obedecendo a seqüência crescente de numeração. Além do instrumento que determinou o diâmetro anatômico, intercalou-se entre um instrumento e outro, irrigação de solução de hipoclorito de sódio a 0,5\%. Os instrumentos de calibres imediatamente superiores ao último instrumento que percorreu todo 0 comprimento de trabalho tiveram recuos sucessivos de 1, 2 e 3 milímetros 
respectivamente. Durante o recuo do escalonamento, foi sempre recapitulado o canal com o último instrumento que percorreu todo o comprimento de trabalho para desobturação da luz do canal radicular e aplainamento das paredes, sendo este também o último instrumento utilizado durante o preparo químicomecânico.

A cinemática dada a cada instrumento foi de limagem (vai-vem), com exceção do instrumento de memória, ao qual foi empregado um movimento de um quarto de volta no sentido horário, durante a recapitulação.

A obturação dos condutos foi realizada com cones de guta percha principal e acessórios (Dentsply Maillefer, Tulsa, Ohklahoma, USA), respeitando o comprimento de trabalho até o travamento apical. Como cimento obturador foi utilizado o material Endofill (Dentsply Maillefer, Tulsa, Ohklahoma, USA). Ao término da obturação dos canais, os dentes foram novamente radiografados seguindo a mesma técnica já descrita anteriormente (figura 07).

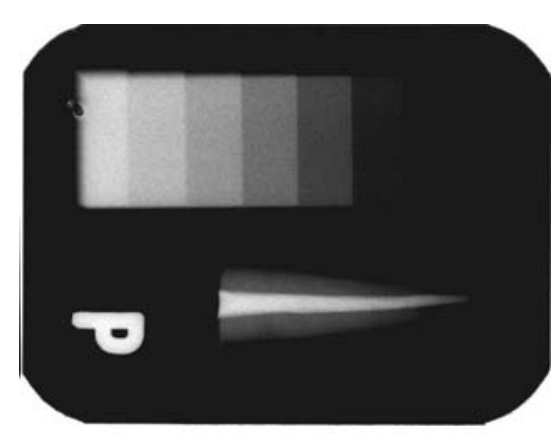

Figura 07: Radiografia após tratamento endodôntico

O preparo dos condutos para confecção dos NMFs foi realizado com brocas de Peeso (FKG Dentaire, La Chaux-de-Fonds, Swiss) e micromotor (Dabi- Atlante) respeitando o comprimento do preparo em 2/3 do comprimento de trabalho. Para determinar esse comprimento de trabalho, as medidas do 
conduto radicular foram feitas com o auxílio de um paquímetro digital (Absolute, Mitutoyo - São Paulo - SP - Brasil; Tabela 01) e os dentes foram novamente radiografados (figura 08$)$.

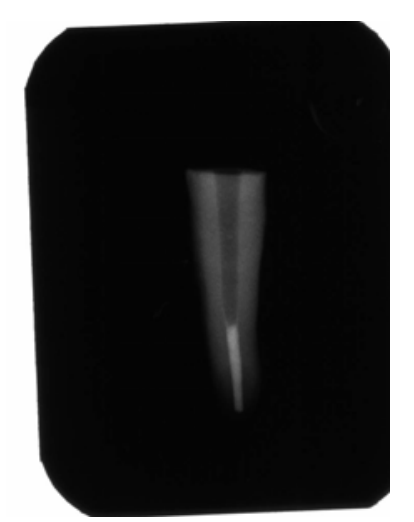

Figura 08: Radiografia do preparo do conduto radicular

Tabela 01 - Comprimento dos dentes

\begin{tabular}{ccc}
\hline Dente & $\begin{array}{c}\text { Comprimento de } \\
\text { Trabalho }(\mathrm{mm})\end{array}$ & $\begin{array}{c}\text { Comprimento do } \\
\text { Preparo }(\mathrm{mm})\end{array}$ \\
\hline 1 & 20 & 13 \\
3 & 18 & 11,60 \\
4 & 15 & 9,86 \\
5 & 15 & 10 \\
6 & 19 & 12,57 \\
7 & 18 & 11,05 \\
8 & 19 & 12,40 \\
9 & 20 & 12,48 \\
10 & 15 & 9,83 \\
\hline
\end{tabular}

Para a realização dos moldes foi criado um protocolo para padronização do posicionamento da moldeira e da força aplicada sobre o material de moldagem. Para isso, utilizou-se um delineador, em que, em sua haste vertical foi adaptada uma moldeira de estoque parcial de forma que permitisse o 
posicionamento do material de moldagem em uma mesma direção de inserção e retirada. Outra moldeira de estoque foi preenchida com resina acrílica autopolimerizável (Clássico - São Paulo, SP, Brasil) e fixada na base do delineador, tendo ao centro uma perfuração para que os diferentes dentes fossem fixados (Figura 09A) e dois cilindros de resina de 1 centímetro para permitir que as moldagens fossem inseridas todas até uma mesma profundidade (Figura 09B).

Os dentes foram fixados na perfuração da moldeira da base do delineador com o auxílio de cera para escultura (Babinete Indústria e Comércio de Ceras Ltda, Maringá, PR, Brasil) previamente aquecida. A técnica de moldagem utilizada com os dois materiais e suportes intra-radiculares foi a da dupla impressão em que um molde preliminar é obtido com o material de alta viscosidade que é refinado em seguida com o material de baixa viscosidade. Para permitir a padronização do espaço para o material de baixa viscosidade após a obtenção do molde com o material de alta viscosidade, foi construído um casquete em resina acrílica (Clássico) como alívio, que era colocado sobre o dente a ser moldado (Figura 09C).
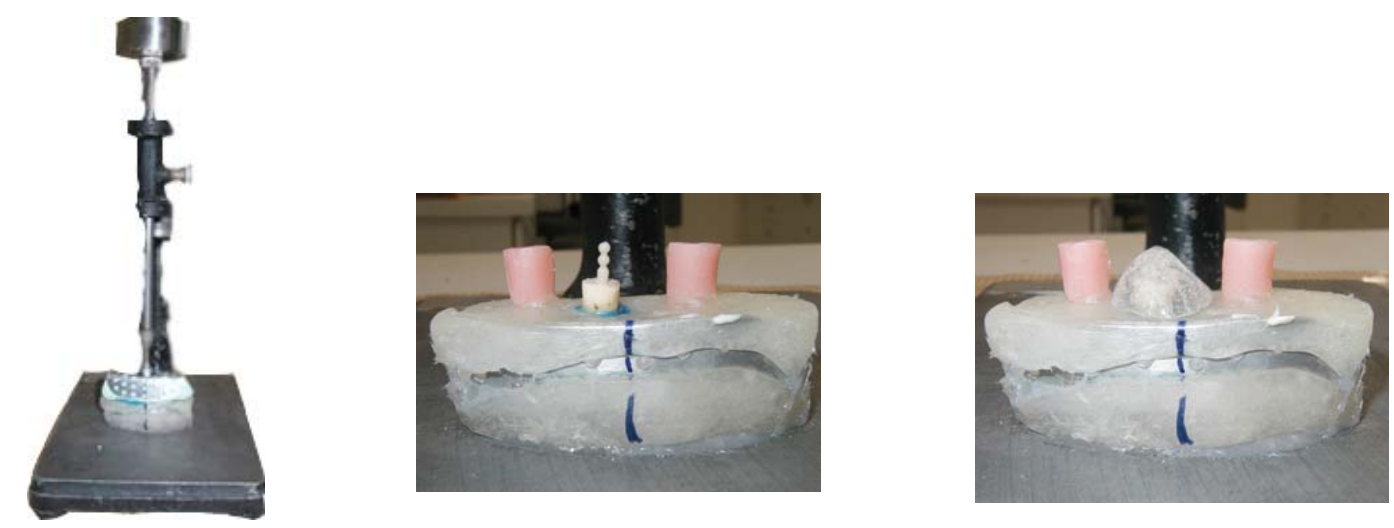

Figura 09: A - delineador com peso de 380 gramas na parte superior, moldeira e base de resina na parte inferior; $\mathbf{B}$ - dente posicionado e stops de resina acrílica; $\mathbf{C}$ casquete de resina 
Os materiais foram proporcionados e manipulados seguindo rigorosamente as recomendações dos fabricantes. Após a manipulação, levava-se o material em posição respeitando o limite imposto pelos cilindros de resina acrílica e, para padronizar a força aplicada durante o ato da moldagem, após a colocação dos materiais de alta e baixa viscosidade, sobre a haste vertical do delineador, foi aplicado um peso de 380 gramas, que foi mantido durante todo o tempo de presa dos materiais, segundo as recomendações dos fabricantes.

Após a obtenção do molde com material de alta viscosidade, o alívio sobre o dente foi removido e utilizou-se o material de baixa viscosidade para moldar o conduto intra-radicular. Antes, porém, foi necessário preparar os suportes que seriam utilizados, de maneira que, quando utilizada a agulha hipodérmica como suporte intra-radicular, inicialmente foram realizadas retenções mecânicas em sua haste com disco de carburundum e micromotor (Dabi-Atlante).

Depois de ajustados, os suportes foram posicionados no interior do canal radicular e, após o correto preparo do material de moldagem de baixa viscosidade, com o auxílio de uma seringa de moldagem o material foi levado ao interior do conduto, em quantidade suficiente para alcançar o ápice intraradicular, extravasando o material com a retirada gradual da seringa até preencher todo o interior do conduto. A moldeira, com o molde inicial com material de alta viscosidade, foi posicionada na mesma posição anteriormente ocupada e após o tempo de presa do material, o conjunto foi removido, sem a realização de movimentos de báscula, obtendo assim o molde final. 
Em cada dente foram realizados quatro moldes, segundo a técnica e 0 material utilizado (Figuras 10A, B, C, D, E, F, G, H).
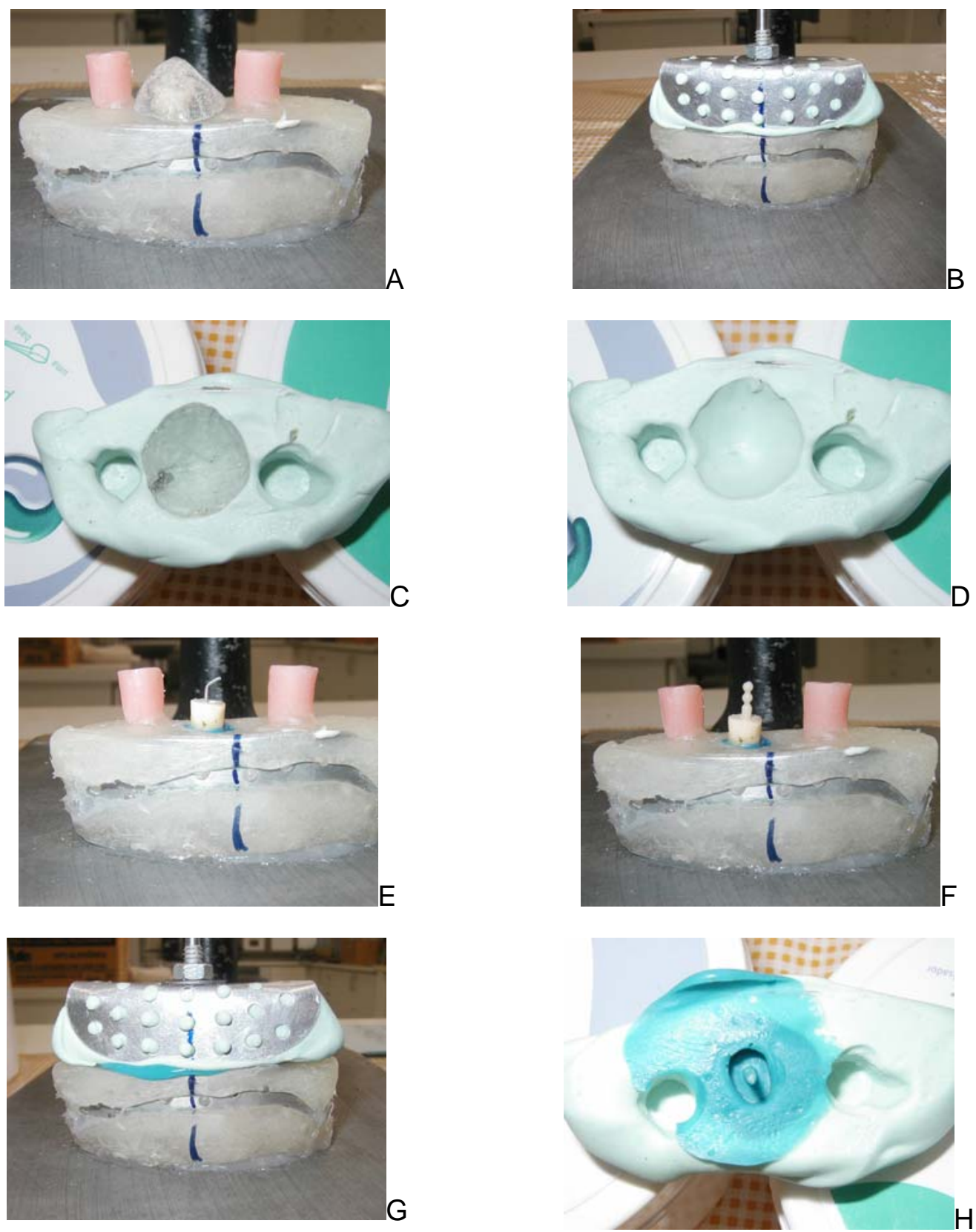

Figura 10: A - seqüência de moldagem: posicionamento do casquete de resina (alívio); $\mathbf{B}$ - moldagem com material de alta viscosidade; $\mathbf{C}$ - casquete de resina (alívio) no molde; $\mathbf{D}$ - remoção do casquete de resina (alívio) do molde; $\mathbf{E}$ - posicionamento do suporte intra-radicular (agulha hipodérmica); $\mathbf{F}$ - posicionamento do suporte intra-radicular (pinjet); G - moldagem com material de baixa viscosidade; $\mathbf{H}$ - molde final 
Dessa forma, criou-se quatro grupos experimentais, conforme a seguinte seqüência (Tabela 02):

Tabela 02 - Seqüência dos grupos experimentais:

\begin{tabular}{ccc}
\hline Grupo & Material & Suporte intra-radicular \\
\hline A & Silicona polimerizada & Agulha hipodérmica \\
B & por adição & Pinjet \\
\hline C & $\begin{array}{c}\text { Silicona polimerizada } \\
\text { por condensação }\end{array}$ & Agulha hipodérmica \\
& & Pinjet \\
\hline D & & \\
\hline
\end{tabular}

Após a obtenção dos moldes, os modelos foram obtidos em gesso especial Durone IV (Dentsply Indústria e Comércio Ltda, Petrópolis, RJ, Brasil) na relação água/pó $=0.19$ para a área dos condutos radiculares e para o restante do modelo foi utilizado o gesso pedra Rio (Orlando Antonio Bussioli ME, Rio Claro, SP, Brasil) na relação água/pó=0.33 (figura 11).

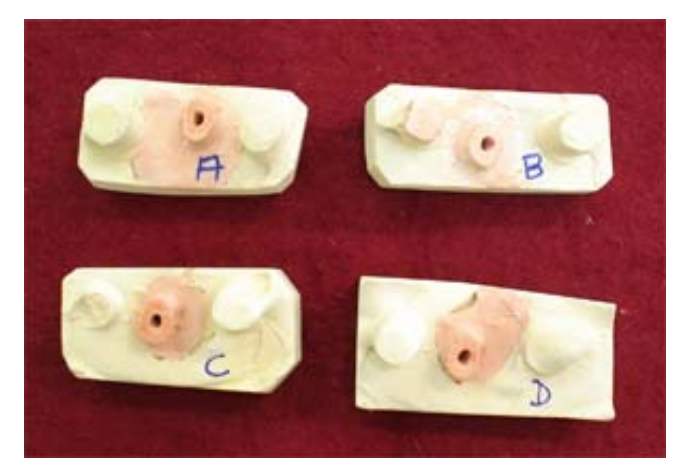

Figura 11: modelos de gesso

Após a presa do gesso e aguardado o tempo de $24 \mathrm{~h}$ da obtenção dos modelos, iniciou-se a escultura dos pinos em resina Duralay (Reliance Dental Mfg.Company, Worth, III, U.S.A) Para isso, com um pincel longo e fino aplicouse uma camada de lubrificante fornecido pelo mesmo fabricante, no interior do conduto. Pela técnica do pincel (NEALON, 1952), a resina acrílica foi levada ao interior do conduto, preenchendo-o totalmente. Imediatamente após, introduziu- 
se na resina um pino plástico para modelagem intra-radicular, no intuito de facilitar a remoção da resina do interior do conduto. Aguardou-se a polimerização da resina acrílica até a fase borrachóide. Suaves e pequenos movimentos de retirada e recolocação do pino no interior do conduto foram feitos até a polimerização final da resina, a fim de não permitir aderência da resina às paredes do conduto. Completado o ciclo da polimerização da resina, o pino foi removido e analisado quanto a eventuais falhas. Se necessário, uma nova camada de resina era acrescentada (figura 12).

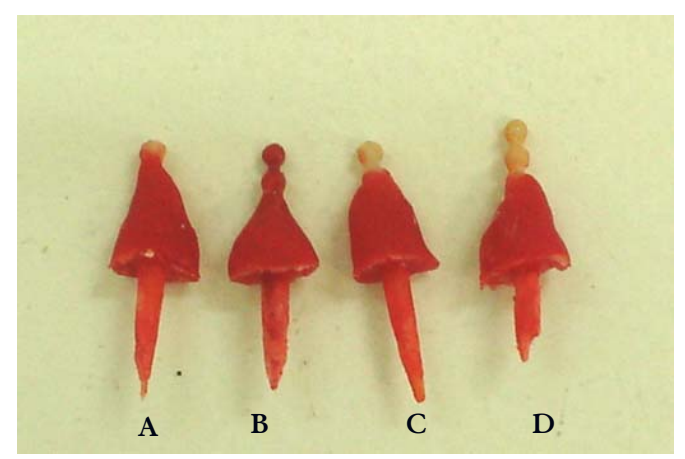

Figura 12: escultura dos núcleos em duralay

Em seguida, os pinos em resina foram incluídos em revestimento (Termocast - Polidental - Cotia - SP - Brasil). Após a presa do material, o conformador de cadinho e o anel de silicone foram removidos com cuidado, permanecendo o cilindro de revestimento para ser empregado na seqüência do processo.

O bloco de revestimento foi colocado no interior de um forno (Forno EDG 1800 - EDG Equipamentos - São Carlos - SP - Brasil) pré-aquecido entre 750 e $850^{\circ} \mathrm{C}$. Aguardou-se 15 minutos a essa temperatura e em seguida o forno foi ajustado para a temperatura final de $950^{\circ} \mathrm{C}$, temperatura em que o anel permaneceu por 30 minutos, para completa distribuição de calor no cilindro. 
A centrífuga elétrica (Powercast 1700 - EDG Equipamentos - São Carlos - SP - Brasil) foi utilizada para injeção da liga líquida. Para a obtenção dos NMFs foi utilizada uma liga de Cu-Al (Aje Goldent Comercial Ltda, São Paulo, SP, Brasil). O cadinho e os botões de liga foram dispostos no aparelho e a fonte de calor aplicada para fusão das ligas foi um maçarico gás/oxigênio (Maçarico EDG - EDG Equipamentos - São Carlos - SP - Brasil). Com o cilindro de revestimento posicionado na máquina de fundição, a centrifugação foi liberada para permitir a entrada do metal líquido no interior do revestimento promovendo o preenchimento do molde.

Para remoção dos NMFs do interior do cilindro de revestimento, foi feita a imersão deste em água e, com um instrumento adequado, retirou-se o material refratário do núcleo metálico. Após acabamento, o canal de alimentação foi removido e os núcleos foram jateados com alumina a $125 \mu \mathrm{m}$ (figura 13). A fidelidade de cópia das técnicas de moldagem utilizadas foi avaliada por meio de análise radiográfica e visual.

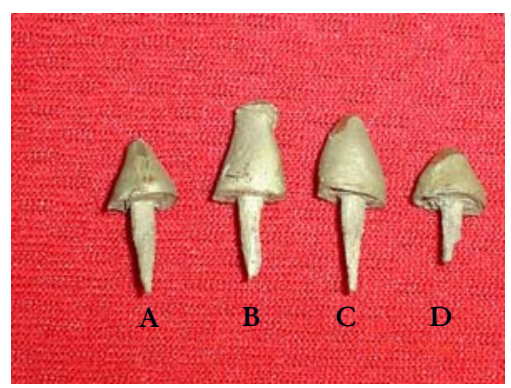

Figura 13: núcleos fundidos

Para a análise radiográfica, após a obtenção dos NMFs, estes foram colocados nos respectivos condutos e nova radiografia foi realizada seguindo o protocolo anteriormente descrito.

Em seguida, as radiografias foram digitalizadas em resolução de 600 dpi. As imagens foram analisadas em Software ImageLab (Softium - São Paulo 
- SP - Brasil) (Fig. 14 A e B) de maneira que foram medidas a extensão de todo o conduto radicular (da cervical do dente até o final do preparo do conduto - (Fig. 15 A, B, C e D) e a área do núcleo adaptada ao canal (Fig. 16 A, B, C e D). Para verificação da adaptação, calculou-se a porcentagem da extensão do canal que o núcleo ocupava (Tabela 3). Por exemplo:
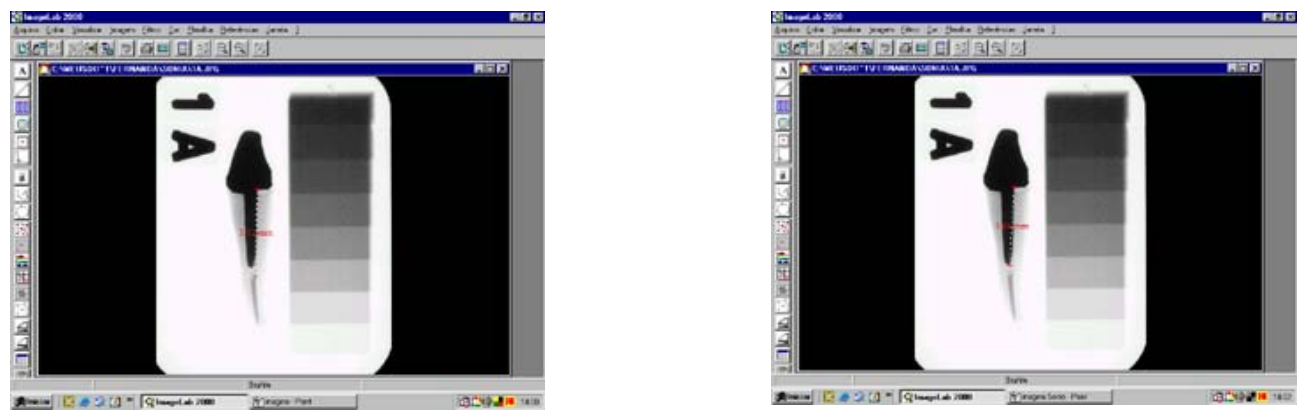

Figura 14: Leitura da radiografia no Programa Image lab A - comprimento do conduto; $\mathbf{B}$ - comprimento do núcleo;
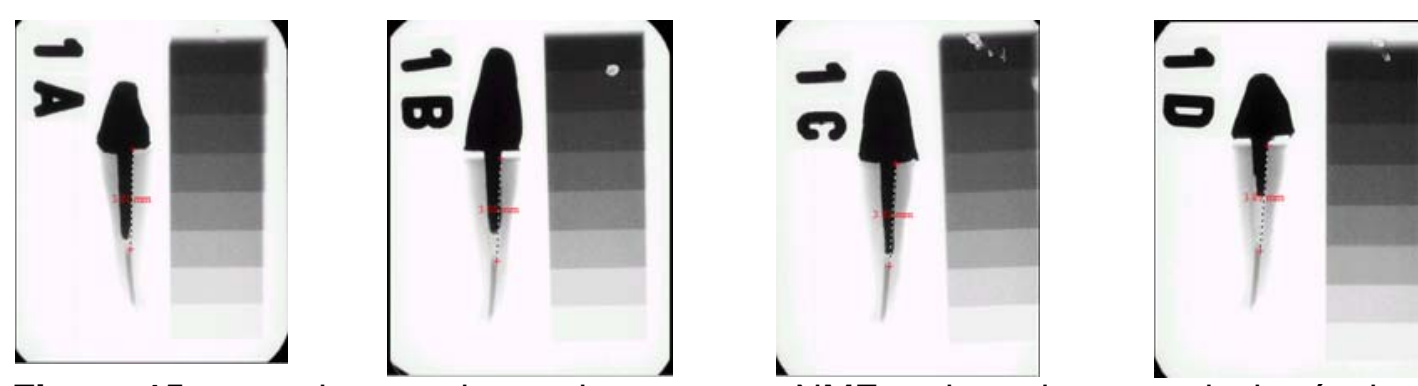

Figura 15: comprimento do conduto com os NMFs adaptados a partir da técnica de moldagem feita com: 1A- silicona polimerizada por adição e agulha hipodérmica; 1B - silicona polimerizada por adição e pinjet; 1C - silicona polimerizada por condensação e agulha hipodérmica; 1D - silicona polimerizada por condensação e pinjet
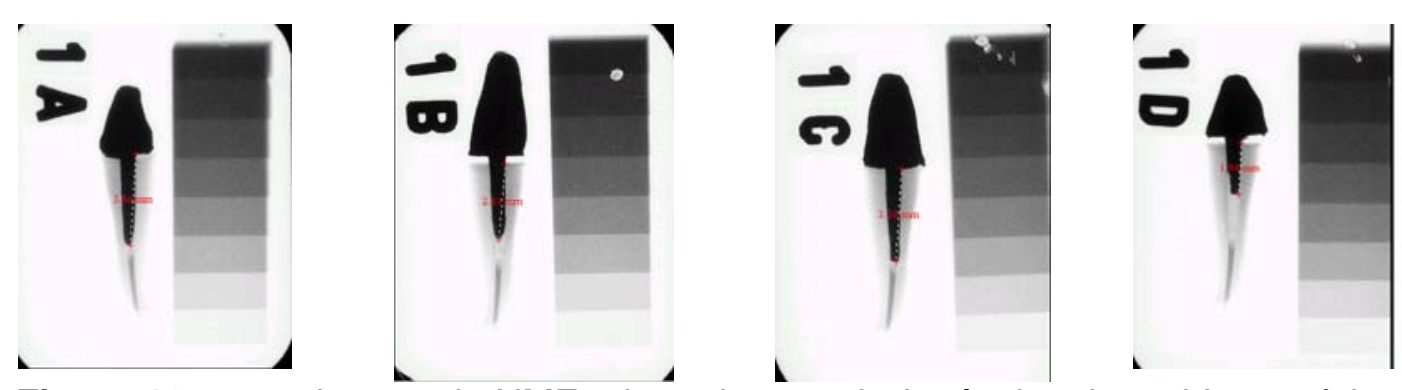

Figura 16: comprimento do NMF adaptado a partir da técnica de moldagem feita com: 1A- silicona polimerizada por adição e agulha hipodérmica; 1B - silicona polimerizada por adição e pinjet; $1 \mathbf{C}$ - silicona polimerizada por condensação e agulha hipodérmica; 1D - silicona polimerizada por condensação e pinjet 
Tabela 03 - comprimento do conduto, núcleo e porcentagem da extensão do canal que o núcleo ocupa

\begin{tabular}{ccccc}
\hline \multicolumn{2}{c}{ Dente } & Conduto $(\mathbf{m m})$ & Núcleo $(\mathbf{m m})$ & Porcentagem \% \\
\hline \multirow{1}{*}{$\mathbf{1}$} & A & 3,81 & 3,46 & 90,81 \\
& B & 3,80 & 2,83 & 74,47 \\
& C & 3,82 & 3,39 & 88,74 \\
& D & 3,85 & 1,94 & 50,39 \\
\hline
\end{tabular}

Para a análise microscópica, os dentes foram incluídos em resina acrílica (Clássico) (figura 17) e depois cortados no sentido longitudinal (figura 18) em aparelho SYJ-150 Digital Low Speed Diamond Saw (MTI Corporation, Califórnia, USA) (figura 19)

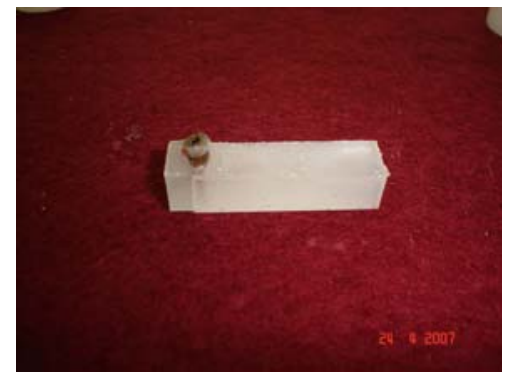

Figura 17: Inclusão do dente na resina acrílica

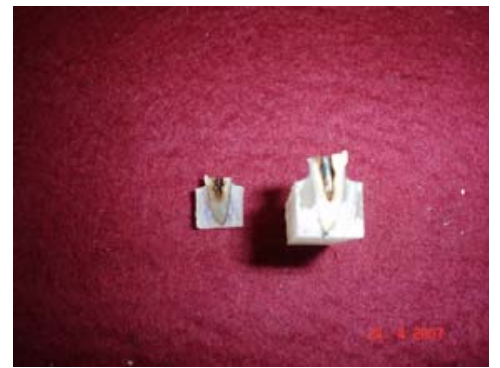

Figura 18: Corte do dente

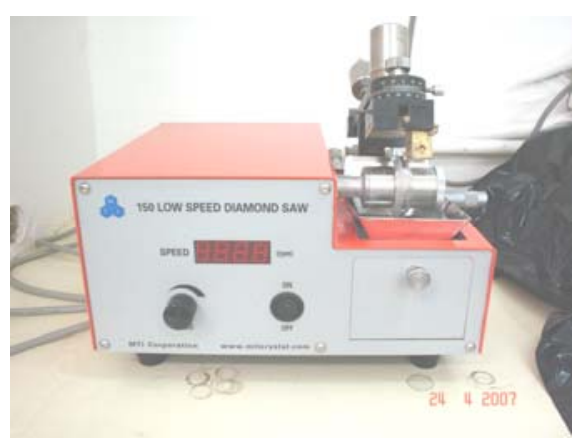

Figura 19: Aparelho SYJ-150 Digital Low Speed Diamond Saw

Em seguida, os núcleos foram adaptados nos condutos (figura $20 \mathrm{~A}, \mathrm{~B}$, C e D) e analisados em microscópio de dupla coordenada (Mesurescope 
Nikon, Nippon Kogaku K.K., Tokyo, Japão), com lente de aumento objetiva de 15X e precisão de 0,001mm (figura 21).
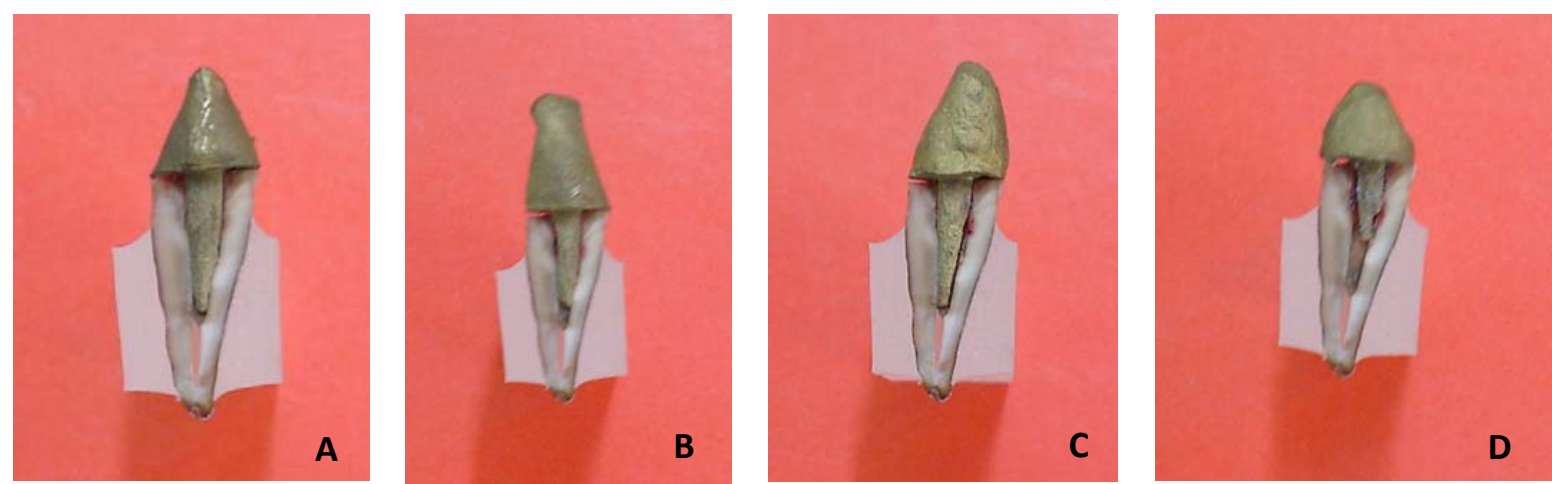

Figura 20: adaptação do NMF feito a partir da técnica de moldagem feita com: A silicona polimerizada por adição e agulha hipodérmica; $\mathbf{B}$ - silicona polimerizada por adição e pinjet; C - silicona polimerizada por condensação e agulha hipodérmica; D silicona polimerizada por condensação e pinjet

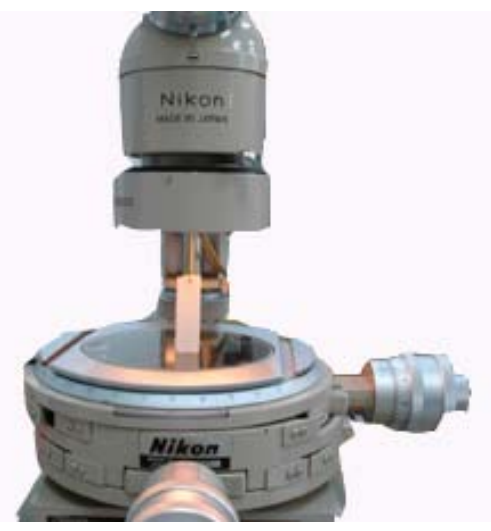

Figura 21: Microscópio de dupla coordenada

Foram feitas as medidas da extensão de todo o conduto radicular (da cervical do dente até o final do preparo do conduto - Figura 22) e, após a colocação do núcleo em posição, foi medida a distância entre o final do núcleo ao início da obturação (Figura 23). 


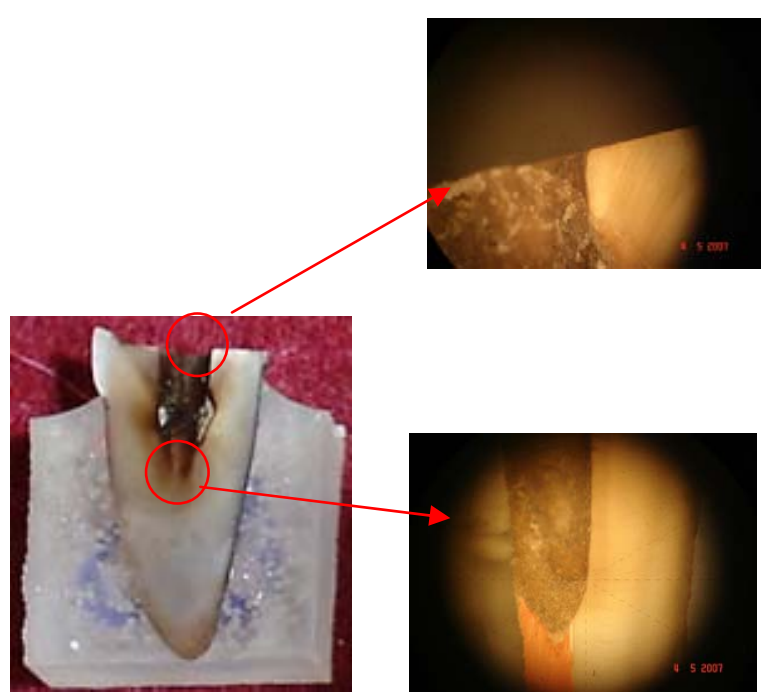

Figura 22: Medida do conduto radicular da cervical até o final do preparo

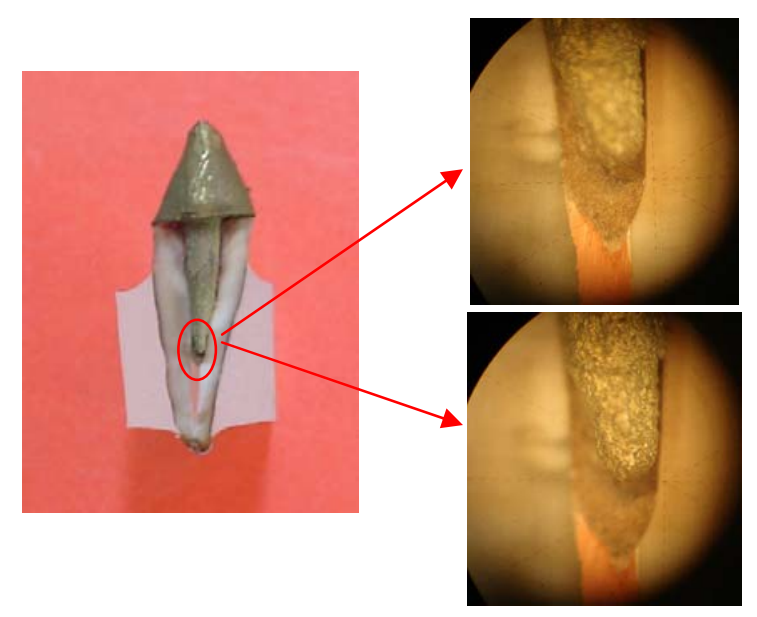

Figura 23: medida da distância entre o final do núcleo ao início da obturação

Para calcular a adaptação do núcleo no conduto em função da técnica e do material utilizado, inicialmente mediu-se o comprimento do conduto preparado. Em seguida, com o núcleo em posição, mediu-se a distância entre a porção apical do núcleo e do conduto preparado. Obteve-se, a partir dessas medidas, a porcentagem do conduto ocupada pelo núcleo obtido segundo a técnica e o material utilizado. 
5. RESULTADOS 


\section{RESULTADOS}

\subsection{Análise Radiográfica}

As medidas dos condutos radiculares, da extensão do núcleo dentro do canal e a respectiva porcentagem representativa de sua ocupação, em relação ao comprimento do canal, podem ser vistas na Tabela 08 (Apêndice). A partir desses valores, foram calculadas as médias e respectivos desvios-padrão das amostras estudadas e os valores podem ser vistos na tabela 04.

Tabela 04 - Porcentagem de preenchimento dos condutos radiculares pelos NMFs e suas médias e respectivos desvios-padrão, após análise radiográfica

\begin{tabular}{ccccc}
\hline Dente & Grupo A & Grupo B & Grupo C & Grupo D \\
\hline 1 & 98,68 & 85,03 & 98,86 & 84,31 \\
2 & 90,81 & 74,47 & 88,74 & 50,39 \\
3 & 91,64 & 60,30 & 95,82 & 95,73 \\
4 & 79,28 & 74,23 & 83,62 & 86,15 \\
5 & 94,89 & 69,31 & 87,21 & 81,99 \\
6 & 78,29 & 83,50 & 89,26 & 59,54 \\
7 & 92,88 & 96,26 & 93,77 & 69,17 \\
8 & 86,01 & 36,97 & 60,86 & 74,67 \\
9 & 90,23 & 86,36 & 100,00 & 95,91 \\
10 & 100,00 & 75,95 & 98,47 & 98,35 \\
\hline Média & 90,27 & 74,24 & 89,66 & 79,62 \\
\hline Desvio & 7,29 & 16,48 & 11,53 & 16,11 \\
Padrão & & & & \\
\hline
\end{tabular}

De acordo com a tabela 04, pode-se observar que os grupos A e C (molde feito com silicona polimerizada por adição e condensação utilizando como suporte intrarradicular agulha hipodérmica apresentaram porcentagens 
maiores de preenchimento significando uma maior adaptação do NMF no conduto radicular. A análise estatística dos dados (2-way ANOVA, Bonferroni, nível de significância de 95\%) pode ser vista na Tabela 05.

Tabela 05 - Análise estatística dos dados (2-way ANOVA, Bonferroni, nível de significância de 95\%) após análise radiográfica

\begin{tabular}{|c|c|c|c|}
\hline \multirow{2}{*}{\multicolumn{2}{|c|}{ 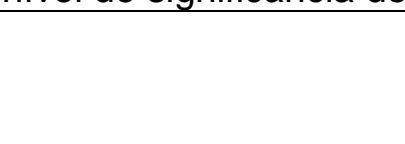 }} & \multicolumn{2}{|c|}{ Técnica } \\
\hline & & Agulha & Pinjet \\
\hline \multirow{2}{*}{ Material } & Adição & $90,27(7,29)$ a $A$ & $74,24(16,48) \mathrm{b} \mathrm{A}$ \\
\hline & Condensação & $89,66(11,53)$ a $A$ & $79,62(16,11)$ a $A$ \\
\hline
\end{tabular}

Letras diferentes, maiúsculas na coluna e minúsculas na linha representam diferenças estatisticamente significantes $(p<0.05)$

A análise dos resultados nos permite verificar que para o fator material não houve diferenças estatisticamente significantes ( $p>0.05)$ na porcentagem de preenchimento do conduto pelo NMF, em relação ao suporte intra-radicular utilizado, ou seja, tanto a silicona polimerizada por condensação quanto a silicona polimerizada por adição apresentaram valores médios de preenchimento semelhantes. Analisando o fator técnica, verificou-se que houve diferença estatisticamente significante $(p<0.05)$ quando utilizada a silicona polimerizada por adição, sendo que os melhores resultados ocorreram para a técnica da agulha hipodérmica. Para a silicona polimerizada por condensação, não houve diferença estatisticamente significante em função da técnica de moldagem utilizada ( $p>0.05$ ). A representação gráfica dos resultados pode ser vista na Figura 24. 


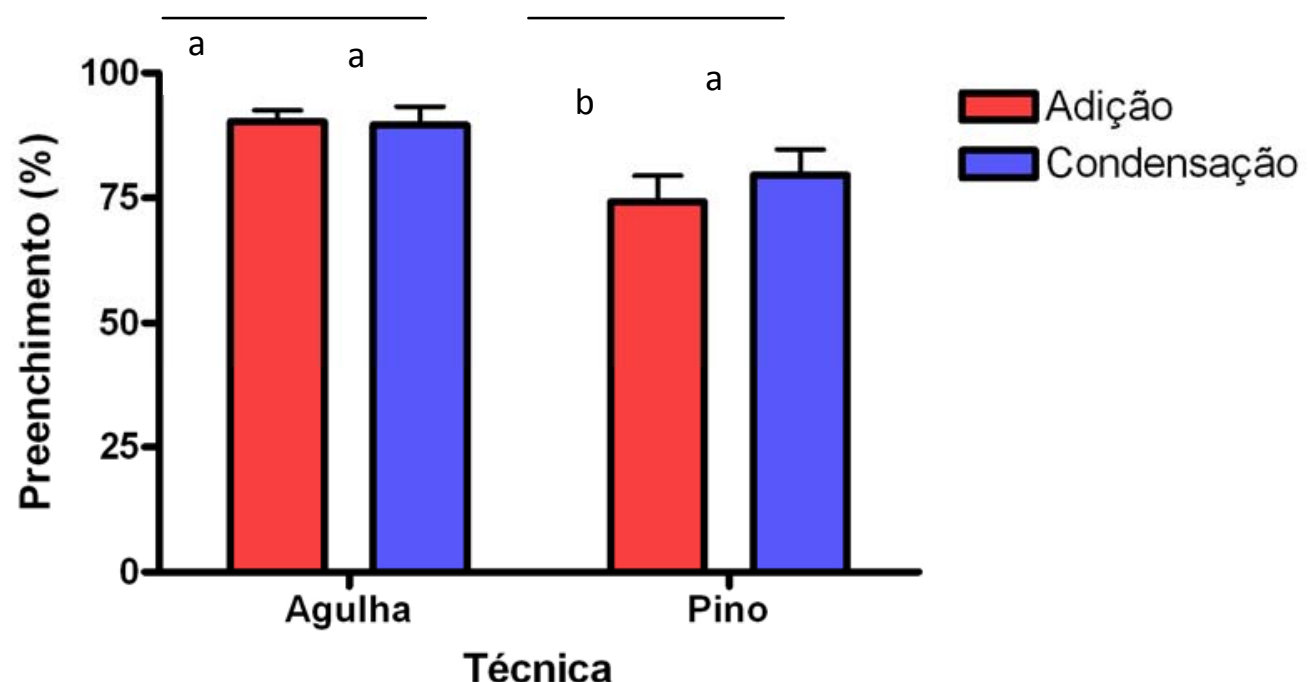

Figura 24 Comparação das médias entre as técnicas de moldagem feitas com silicona polimerizada por adição e condensação utilizando agulha hipodérmica e pinjet, a partir das leituras das imagens radiográficas. Colunas sob as linhas horizontais indicam resultados sem diferença estatisticamente significante $(P>0.05)$. Letras diferentes, comparando mesmo material, indicam resultados estatisticamente significantes $(p<0.05)$

\section{2 - Análise Microscópica}

As medidas dos condutos radiculares, da extensão do núcleo dentro do canal e a respectiva porcentagem representativa de sua ocupação, em relação ao comprimento do canal, podem ser vistas na Tabelas 09 e 10 (Apêndice). A partir desses valores, foram calculadas as médias e respectivos desviospadrão das amostras estudadas e os valores podem ser vistos na tabela 06. 
Tabela 06 - Porcentagem de preenchimento dos condutos radiculares pelos NMFs e suas médias e respectivos desvios-padrão, após análise microscópica.

\begin{tabular}{ccccc}
\hline Dente & Grupo A & Grupo B & Grupo C & Grupo D \\
\hline 1 & 100,00 & 96,47 & 100,00 & 95,63 \\
2 & 98,48 & 90,59 & 99,46 & 62,28 \\
3 & 99,67 & 62,60 & 98,57 & 91,93 \\
5 & 87,52 & 86,05 & 99,41 & 89,36 \\
6 & 99,86 & 75,92 & 97,87 & 99,06 \\
7 & 98,39 & 88,54 & 100,00 & 67,29 \\
8 & 99,12 & 97,73 & 94,39 & 70,28 \\
9 & 92,84 & 62,33 & 67,88 & 80,11 \\
10 & 99,88 & 89,49 & 100,00 & 100,00 \\
\hline Média & 100,00 & 75,02 & 87,75 & 99,14 \\
\hline Desvio & 97,58 & 82,47 & 94,53 & 85,51 \\
\hline Padrão & 4,14 & 12,88 & 10,12 & 14,42 \\
\hline
\end{tabular}

De acordo com a tabela 06, pode-se observar que os grupos A e C (molde feito com siliconas polimerizadas por adição e condensação utilizando como suporte intra-radicular agulha hipodérmica) apresentaram porcentagens maiores de preenchimento significando uma maior adaptação do NMF no conduto radicular. A análise estatística dos dados (2-way ANOVA, Bonferroni, nível de significância de 95\%) pode ser vista na Tabela 07.

Tabela 07 - Análise estatística dos dados (2-way ANOVA, Bonferroni, nível de significância de 95\%) após análise microscópica.

\begin{tabular}{cccc}
\hline & \multicolumn{3}{c}{ Técnica } \\
\hline & & Agulha & Pino \\
\hline \multirow{2}{*}{ Material } & Adição & $97,58(4,14)$ a A & $82,47(12,88)$ b A \\
& Condensação & $94,53(10,12)$ a A & $85,51(14,42)$ a A \\
& & & \\
\hline
\end{tabular}

Letras diferentes, maiúsculas na coluna e minúsculas na linha representam diferenças estatisticamente significantes $(p<0.05)$ 
A análise dos resultados nos permite verificar que para o fator material não houve diferenças estatisticamente significantes em relação ao suporte intra-radicular utilizado, ou seja, tanto a silicona polimerizada por condensação quanto a silicona polimerizada por adição apresentaram valores médios de preenchimento semelhantes $(p>0.05)$. Analisando o fator técnica, verificou-se que houve diferença estatisticamente significante $(p<0.05)$ quando utilizada a silicona polimerizada por adição, sendo que os melhores resultados ocorreram para a técnica da agulha hipodérmica. Para a silicona polimerizada por condensação, não houve diferença estatisticamente significante em função da técnica de moldagem utilizada $(p>0.05)$. A representação gráfica dos resultados pode ser vista na Figura 25.

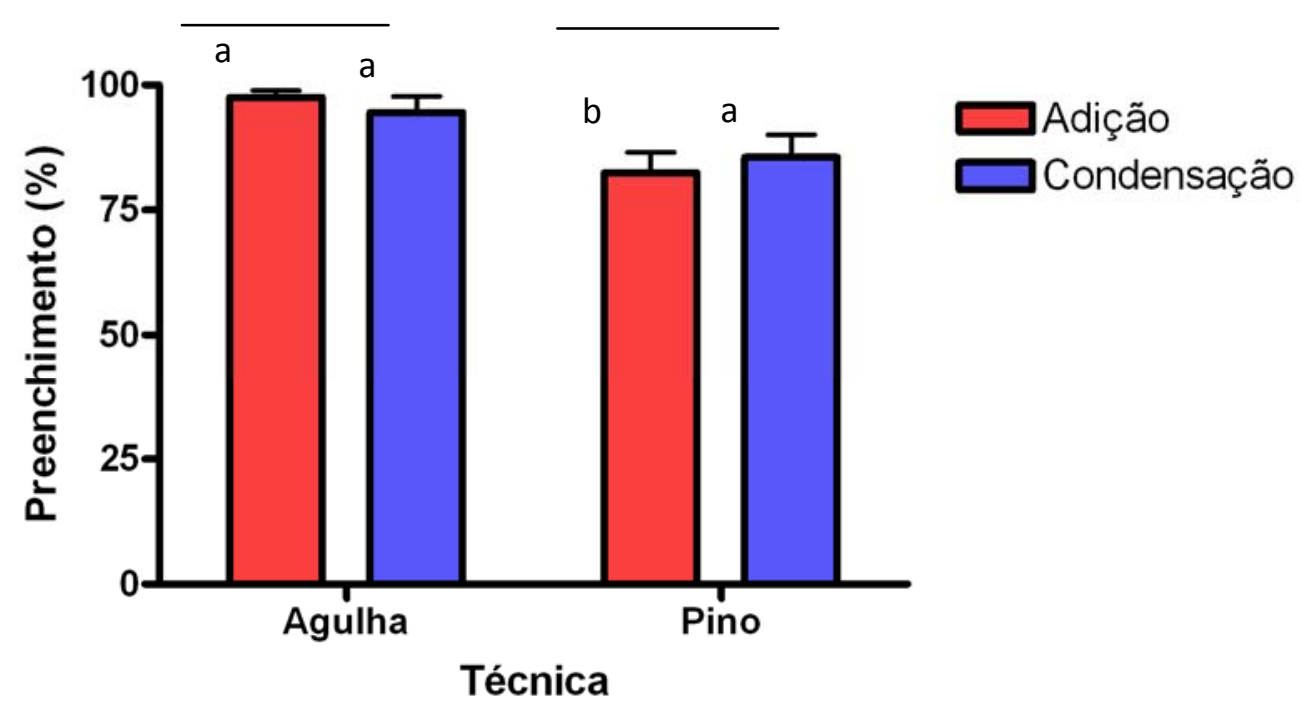

Figura 25: Comparação das médias entre as técnicas de moldagem feitas com silicona polimerizada por adição e condensação utilizando agulha hipodérmica e pinjet, a partir das leituras feitas em microscópio. Colunas sob as linhas horizontais indicam resultados sem diferença estatisticamente significante $(P>0.05)$. Letras diferentes, comparando mesmo material, indicam resultados estatisticamente significantes $(p<0.05)$ 
6. DISCUSSÃO 


\section{DISCUSSÃO}

A moldagem dos dentes suporte e das estruturas adjacentes sobressaise pelo seu valor estratégico, pois representa a passagem da situação clínica para a bancada de laboratório na forma de modelos (MEZZOMO E FRASCA, 1994). Esta transposição tem que ocorrer da forma mais fiel possível para que se atinjam todos os objetivos de uma reabilitação. Assim, a função de um material de moldagem é registrar de forma mais precisa e exata as dimensões dos preparos dentais e tecidos bucais.

Materiais adequados para moldagens precisas, aliados a técnicas corretas, diminuem consideravelmente a possibilidade de erros (KLEINE et al., 2002) como a má adaptação dos NMFs. Tan (1995) salientou que, desde a primeira moldagem até a instalação definitiva da prótese não há como evitar a incorporação de pequenas distorções ao longo das diversas fases de elaboração da prótese. Contudo, a observação correta de técnicas eficazes e o uso de materiais de excelente qualidade permitem a execução de trabalhos com o mínimo de erros possíveis (KLEINE et al., 2002).

Embora a capacidade dos ensaios in vitro em predizerem o desempenho clínico seja questionável, estes testes são considerados de fundamental importância para o desenvolvimento de novas técnicas como também para a adaptação dos NMFs, uma vez que a rápida evolução dos materiais de moldagem e produtos dificultariam sua avaliação a longo prazo. $\mathrm{O}$ presente estudo foi delineado de maneira a analisar, in vitro, em dentes humanos extraídos, a adaptação de NMFs pela observação radiográfica e microscópica. A decisão de se utilizar dentes humanos baseou-se no princípio 
de que eles poderiam representar a melhor opção para simular as situações clínicas para dentes tratados endodonticamente (MENDOZA et al.,1997; SIDOLI et al., 1997; MARTINEZ-INSUA et al, 1998; NEWMAN et al., 2003).

A silicona de reação por adição vem gradativamente conquistando a preferência dos profissionais, principalmente pela estabilidade dimensional e por não produzirem subprodutos voláteis durante a polimerização. Segundo dados publicados no The Dental Advisor (1998), este material é o mais utilizado nos Estados Unidos, compreendendo 51\% da preferência dos americanos contra 2\% para as siliconas polimerizadas por condensação. No Brasil, entretanto, a silicona polimerizada por condensação tem sido o material mais utilizado por $63 \%$ entre os profissionais, enquanto que a silicona polimerizada por adição representa a pequena preferência de 7,4\% (EDUARDO e MATSON, 1996).

Para avaliação da adaptação dos núcleos, optou-se por utilizar duas metodologias: radiograficamente e microscopicamente. A primeira técnica é a mais indicada para uma análise radiográfica do material (TOYOOKA, et al., 1993; RUBO e EL-MOWAFI, 1998), ou seja, o profissional, para se certificar que o núcleo está adaptado no conduto, ocupando toda a extensão preparada para recebê-lo, deve fazer uma tomada radiográfica. Entretanto, devido à limitação imposta pela radiografia quanto às imagens obtidas, como a sobreposição de imagens de estruturas (AUN et al, 1978; UPDEGRAVE,1959) e a ocorrência de distorções (LANGLAND et al, 1966), realizou-se a análise microscópica para certificação da situação real da adaptação dos núcleos. 
Radiograficamente verificou-se que a técnica utilizando a agulha hipodérmica e silicona polimerizada por adição mostrou-se mais eficaz para a reprodução do conduto radicular, permitindo a obtenção de núcleos fundidos mais bem adaptados. Com a silicona polimerizada por condensação o comportamento dos suportes intra-radiculares foi semelhante estatisticamente. O mesmo ocorreu quando a adaptação foi analisada microscopicamente.

Segundo estudos de Pinto (1992) e Stackhouse Jr (1970), a ausência de espaço para escoamento do material leve, induz uma pressão interna durante a moldagem, impedindo a saída do ar de dentro do conduto radicular. Este fenômeno ocorre na técnica de moldagem quando utilizamos o pinjet como suporte intra-radicular, durante a injeção do material leve e a colocação do acessório; a formação da pressão interna de ar contido no interior do conduto levará a formação de "bolhas", prejudicando de maneira severa a adaptação do NMF. Essa ocorrência pode ser explicada pela propriedade da impenetrabilidade da matéria, segundo a qual dois corpos não podem ocupar ao mesmo tempo o mesmo lugar no espaço (NEWTON, 1673).

"Nós percebemos que os corpos que manuseamos são impenetráveis e daí concluímos que a impenetrabilidade deve ser uma propriedade universal de todos os corpos, quaisquer que sejam." (NEWTON, 1673)

Entretanto, quando executamos a técnica utilizando a agulha hipodérmica, o posicionamento da agulha no conduto permitirá a saída do ar contido no interior do canal durante a inserção do material de baixa viscosidade, promovendo melhor escoamento do material, conseqüentemente uma maior precisão na moldagem e melhor adaptação do NMF. 
Tanto à análise radiográfica como microscópica, verificou-se que o fator material não teve significância nos resultados, ou seja, considerando-se uma só técnica para obtenção do molde (agulha ou pinjet) não houve diferença estatisticamente significante ( $p>0,05)$ na adaptação dos núcleos, independente do material utilizado. Isso nos permite verificar que o fator primordial que interferiu na obtenção de peças adaptadas foi a técnica.

Nas duas análises realizadas, altos valores de desvio-padrão foram encontrados, principalmente para a técnica do pinjet. Isso pode ser explicado devido à dificuldade de obtenção do molde segundo a técnica indireta para confecção do núcleo metálico. Apesar desta técnica oferecer vantagens como a redução do tempo de permanência na cadeira odontológica (MORTON e STEVEN, 1997), permitindo maior conforto ao paciente, trata-se de uma técnica difícil de realizar. Dessa forma, valoriza-se ainda mais a busca por técnicas que permitam maior reprodução de detalhes e, conseqüentemente, maior adaptação da peça fundida.

Um fator que não pode ser esquecido é que o processo de fundição introduz um complexo grupo de variáveis como: escultura, revestimento, fundição da liga metálica entre outros, e que os efeitos destas variáveis são imprevisíveis (BONACHELA,1991). Segundo Araújo (1989), o processo de fundição apresenta uma variabilidade muito grande, podendo diluir a melhoria obtida com materiais de moldagem mais precisos. No entanto, no presente estudo o método foi padronizado, sendo que os núcleos foram esculpidos pela técnica do pincel com resina Duralay (Reliance Dental Mfg.Company, Worth, III, U.S.A) (NEALON, 1952), por ter uma melhor estabilidade dimensional em relação a cera para escultura (Babinete Indústria e comércio de Cera Ltda, 
Maringá, PR, Brasil), e todos os materiais e técnicas do processo de fundição foram cuidadosamente trabalhados para minimizar o erro.

Com relação à técnica de moldagem empregando agulha hipodérmica como suporte intra-radicular, e por não haver na literatura específica nenhum trabalho relacionado a esta técnica, justifica-se a necessidade de avaliações adicionais em diferentes níveis de pesquisa, inclusive in vivo, a fim de oferecer respaldo para obtenção de melhores resultados clínicos. 
7. CONCLUSÕES 


\section{CONCLUSÕES}

A análise dos resultados permite concluir que:

- Quanto ao material de moldagem utilizado para a obtenção dos moldes com qualquer um dos tipos de suporte intra-radicular, não houve diferença estatisticamente significante $(p>0,05)$ na adaptação do NMF no conduto radicular, tanto segundo a análise radiográfica como microscópica;

- Houve diferença estatisticamente significante $(p<0,05)$ na adaptação do NMF nos condutos radiculares, segundo análise radiográfica e microscópica, quando os mesmos foram obtidos a partir de moldes com silicona polimerizada por adição utilizando agulha hipodérmica como suporte intra-radicular. 
REFERÊNCIAS 


\section{REFERÊNCIAS}

ARAÚJO, C.P.R. Análise da influência do reaquecimento das moldagens de siliconas de adição e mercaptanas sobre a adaptação de fundições em ligas para metalocerâmica. Bauru; 1989 (Tese de Doutorado - Faculdade de Odontologia de Bauru, Universidade de São Paulo)

AUN, C.E.; BERNABÉ, P.F.E. Adaptação da técnica do paralelismo para tomadas radiográficas durante o tratamento endodôntico. Rev Ass Paul Cirurg Dent., v.32, n.2, p.118-127, Mar-Abr. 1978

BONACHELA, W.C. Avaliação das alterações dimensionais de troqueis de sete marcas de gesso (seis tipo IV e uma tipo III) obtidos de moldes de silicona por adição. Bauru; 1991 (Tese de Doutorado - Faculdade de Odontologia de Bauru, Universidade de São Paulo)

BRADEN, M.; ELLIOT, J.C. Characterization of the setting process of silicone dental rubbers. J Dent Res., v.45, n.4, p.1016-1023, July-Aug.1966

CHEE, W.L.; DONOVAN, T.E. Polyvinyl siloxane impression materials a review of properties and techniques. J Prosthet Dent., v.68, n.5, p.728-732, Nov. 1992

CHRISTENSEN,G.J. Posts: necessary or unnecessary?. J Am Dent Assoc., v.127,n.10,p.1522-1526, Oct. 1996

CHRISTENSEN,G.J. Post and cores: state of the art. J Am Dent Assoc., v.129, n.1, p.96-97, Jan. 1998

CLANCY, J.M.S.; SCANDRETT, F.R.; ETTINGER, R.L. Long-term dimensional stability of three current elastomers. J Oral Rehabil., v.10, n.4, p.325-333, July 1983.

CRAIG, R.G.; URQUIOLA, N.J.; LIU, C. Comparasion of commercial elastomeric impression materials. Oper. Dent., v.15, n.3, p.94-104, May-June 1990 
CULLEN, D.R.; MIKESELL, J.W.; SANDRIK, J.L. Wettability of elastomeric impression materials and voids in gypsum casts. J Prosthet Dent., v.66, n.2, p.261-265, Aug.1991

Dental Advisor. Brasil 1998 fev; 5(1)

EDUARDO, C.P.; MATSON, E. Moldagem em prótese unitária. São Paulo. Santos; 1996.

HELFER, A.R.; SCHILDER, H. Determination of the moisture content of vital and pulpless teeth. Oral Surg., v.34, n.4, p.661-670, Oct. 1972.

KLEINE, A.; NÓBILO, M.A.A.; HENRIQUES, G.E.P.; MESQUITA, M.F. Influência de materiais de moldagem e de técnicas de transferência em implantes osseointegrados na precisão dimensional linear de modelos de gesso. RPG Revista da pós graduação, v.9, n.4, p.349-357, Out-Dez.2002

KLOOSTER, J.; LOGAN, G.I.; TJAN, A.H.L. Effectes of strain rate on the behavior of elastomeric impression. J Prosthet Dent., v.66, n.3, p.292-298, Sept.1991

KRAMMER, R. A time-saving method for indirect fabrication of cast posts and cores. J Prosthet Dent., v.76, n.2, p.209-211, Aug.1996

LACY, A.M.; FUKUI, H.; BELLMAN, T.; JENDRESEN, M.D. Time-denpendent accuracy of elastomer impression materials. Part II: polyether, polysulphides and polyvinylsiloxane. J Prosthet Dent., v.45, n.3, p.329-333, Mar. 1981

LANGLAND, O.E.; SIPPY, F.H. A study of radiographic longitudinal distortion of anterior teeth using the paralleling technique. Oral Surg Oral Med Oral Pathol., v.22, n.6, p.737-749, Dez.1966

MANNING, K.E.; YU, D.C.; YU, K.C.; KWAN, E.W. Factors to consider for predictable post and core build-ups of endodontically treated teeth. Part I. Basic theoretical concepts. J Canadian Dent Assoc., v.61, n.8, p.685-695, Aug 1995 
MARCINAK, C.F.; DRAUGHN, R.A. Linear dimensional changes in addition curing silicone impression materials. J Prosthet Dent., v.47, n.4, p.411-413, Apr. 1982

MARTINEZ-INSSUA, A.; SILVA, L.; RILO. B.; SANTANA, U. Comparison of the fracture resistances of pulpless teeth restore with a cast post and core or carbon fiber post with composite core. J Prosthet Dent., v.80, n.5, p.527-532, Nov. 1998

MCCABE, J.F.; WILSON,H.J. Addition curing silicone rubber impression materials. Br Dent J., v.145, n.1, p.14-20, July 1978

MENDOZA, D.B.; EAKLE, S.; KAHL, E.A.; HO, R. Root reinforcement with a

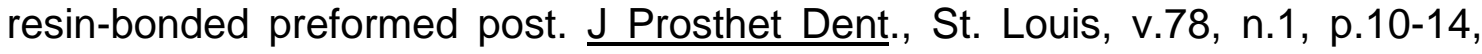
July 1997

MEZZOMO,E.; FRASCA,L.C.F. Moldagens em prótese parcial fixa. In: MEZZOMO,E. Reabilitação oral para o clínico. São Paulo: Santos, 1994.

MORGANO, S.M.; BRACKETT, S.E. Foundation restorations in fixed prosthodontics: current knowledge and future needs. J Prosthet Dent., v.82,n.6, p.643-657, Dec.1999

MORTON D.; STEVEN A. A. Fabrication of multiple posts and cores using a thermoplastic material and an indirect technique: A clinical report $\mathrm{J}$ Prosthet Dent., v.78, n.6, p. 542-544, Dez. 1997.

MYERS, G.E.; PEYTON, F.A. Clinical and physical studies of the silicone

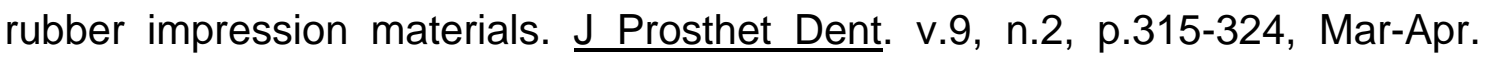
1959.

NASR. H.H.; ISKANDER, F.G. Vertical displacement of the mucosa in bounded edentulous ridges with different elastomeric impression materials and techniques. Egypt Dent J, n. 34, v.1, p.55-71, Jan. 1988. 
NEALON F.H. Acrylic Restorations by the operative nonpressure procedure. $\underline{\mathrm{J}}$ Prosth Dent., v.2, n.4, p.513-527, Jul.1952

NEWMAN, M. P.; YAMAN, P.; DENNISON, J.; RAFTER, M.; BILLY, E. Fracture resistance of endodontically treated teeth restored with composite posts. $\underline{\mathrm{J}}$ Prosthet Dent., v.89, n.4, p.360-367, Apr. 2003

NEWTON, I. The Mathematical Principles of Natural Philosophy Book III vol. 2. London: H. D. Symonds, 1803, 160-162, 1673.

OURIQUE, S.A.M. Colagem de fragmento dentário utilizando reforço intra-canal de fibras cerâmicas flexíveis (GlasSpan). Rev Paul Odontol, ano XXI, n. 2, p.28-32, 1999

PEUTZFELDT, A.; ASMUSSEN, E. Impression materials: effect of hydrophilicit and viscosity on ability to displace water from dentin surfaces. Scand Dent Res, v.96, n.3, p.253-259, June 1988

PHLILLIPS, R.W. Elastic impression material: a summary of a recent conference and analysis of the current status and recent research. $\mathrm{J}$ Prosthet Dent., v.8, n.4, p.650-656, July 1958

PHILLIPS, R.W. Physical properties and manipulation of rubber impression materials. J Am Dent Assoc., v.59, n.3, p.454-458, Sept. 1959

PINTO, J.H.N. Avaliação do desajuste cervical de infra-estruturas metálicas fundidas, obtidas através de técnica de dupla impressão, empregando-se silicona por adição (Provil P e L) com e sem alívio entre materiais. Bauru; 1992. (Monografia de Residência em Prótese Dentária - Hospital de Reabilitação de Anomalias Craniofaciais da USP)

PRATTEN, D.H.; CRAIG, R.G. Wettability of a hydrophilic addition silicone impression material. J Prosthet Dent., v.61, n.2, p.197-202, Feb.1989 
ROSENSTIEL, S.F.; LAND, M.F.; FUJIMOTO, J. Contemporary fixed prosthodontics. St Louis; Mosby, 1995

RUBO, M.H.M.; EL-MOWAFY, O. Radiopacity of Dual-Cured and ChemicalCured Resin-Based Cements. Int J Prosthodont., v.11, n.1, p.70-74, Jan-Fev. 1998

SABBAK, S.A. Indirect fabrication of multiple post-and-core patterns with a vinyl polysiloxane matrix. J Prosthet Dent., v.88, n.5, p.555-557, Nov.2002

SAITO, T.; CAMPOS, T.N.; FERNANDES, I.M.; TORTAMANO, P. Moldagem de preparação dentais com anel de cobre e godiva. Bras Odontol, Rio de Janeiro, v.45, n.5, p.2-10, set/out.1998.

SHILLINGBURG, H.T.; KESSLER, J.C. Princípios da restauração dos dentes tratados endodonticamente. 2 ed. São Paulo. Quintessence, 1991. Cap.1, p.1344.

SIDOLI, G.E.; KING, P.A.; SETCHELL, D.J. An in vitro evaluation of a carbon fiber-based post and core system. J Prosthet Dent., St. Louis, v.78, n.1, p.5-9, July 1997

SILVERSTEIN, W.H. The reinforcement of weakened pulpless teeth. $\underline{\mathrm{J} \text { Prosthet }}$ Dent, Saint Louis, v.14, n.2, p.372-381, Mar-Apr 1964

SKINNER, E.W. The properties and manipulation of mercaptan base and silicone base impression material. Dent Clin North Am., p.685-97, Nov 1958

SMITH, C.T.; SCHUMAN, N. Restoration of endodontically treated teeth: a guide for the restorative dentist. Quintessence Int., v.28, p.457-462, 1997;

STACKHOUSE JR., J.A. The accuracy of stones dies made from rubber impression materials. J Prosthet Dent., v.24, n.4, p.377-386, Oct. 1970 
TAN, K.B. The clinical significance of distortion in implant prosthodontics: is there such a thing as passive fit? Ann Acad Med Singpore, v.24, n.1, p.138-157, Jan.1995

TJAN, A.H.; WHANG, S.B.; MILLER, G.D. Why a rigid tray is important to the putty wash silicone impression method. Calif Dent Assoc J, v.9, n.9, p. 53-58, Sep 1981

TOYOOKA, H.; TAIRA, M.; WAKASA, K.; YAMAKI, M.; FUJITA, M.; WADA, T. Radiopacity of 12 visible-light-cured dental composite resins. J Oral Rehabil., v. 20, n.6, p.615-622, Nov. 1993

UPDEGRAVE, W. J. Simplifying and improving intraoral dental roentgenography. Oral Surg Oral Med Oral Pathol, v.12, n.6, p.704-716, June 1959.

WILLIAMS, P.T.; JACKSON, G.D.; BERGMAN, W. An evaluation of the timedependent dimensional stability of eleven elastomeric impression materials. $\underline{\mathrm{J}}$ Prosthet Dent., v.52, n.1, p.120-125, July 1984

YEH, C.L.; POWERS, J.M.; CRAIG, R.G. Properties od addition type silicone impression materials. J Am Dent Assoc., v.101, n.3, p.482-484, Sept. 1980. 


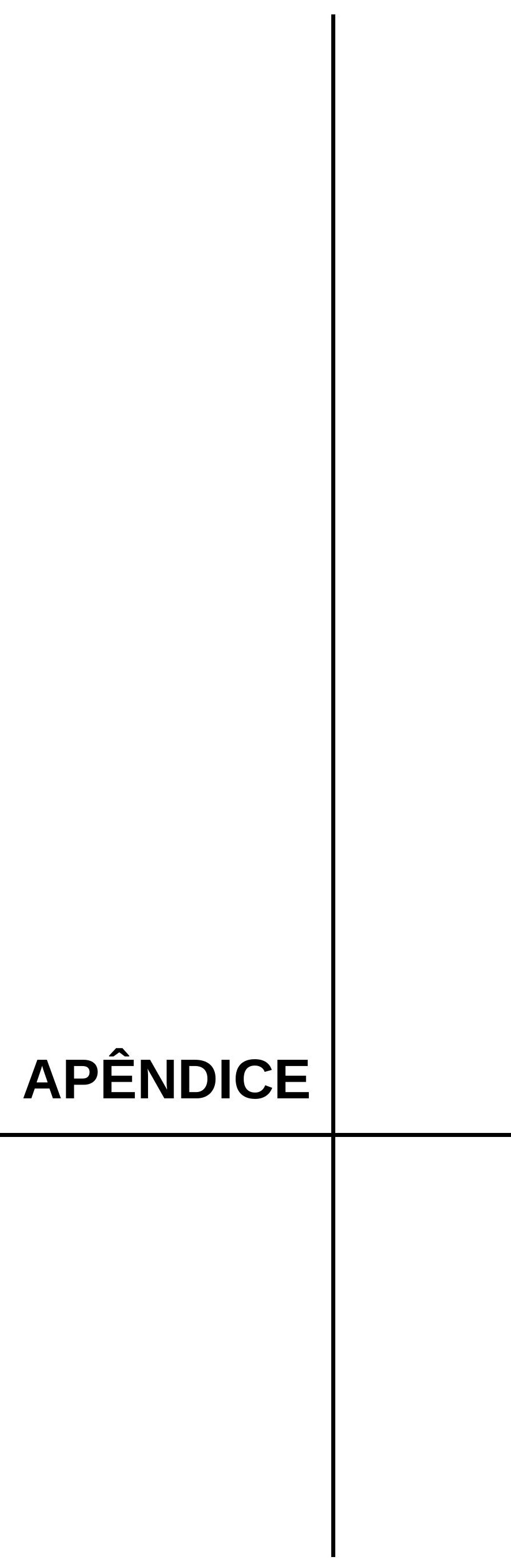




\section{APÊNDICE}

Tabela 08 - Análise Radiográfica: medidas dos condutos radiculares, extensão do núcleo dentro do canal e a respectiva porcentagem representativa de sua ocupação, em relação ao comprimento do canal.

\begin{tabular}{|c|c|c|c|c|}
\hline Dente & Grupo & Conduto (mm) & Pino (mm) & Porcentagem \% \\
\hline & A & 4,56 & 4,5 & 98,68 \\
\hline \multirow[t]{4}{*}{1} & B & 4,41 & 3,75 & 85,03 \\
\hline & C & 4,4 & 4,35 & 98,86 \\
\hline & D & 4,59 & 3,87 & 84,31 \\
\hline & A & 3,81 & 3,46 & 90,81 \\
\hline \multirow[t]{4}{*}{2} & B & 3,8 & 2,83 & 74,47 \\
\hline & C & 3,82 & 3,39 & 88,74 \\
\hline & D & 3,85 & 1,94 & 50,39 \\
\hline & A & 3,35 & 3,07 & 91,64 \\
\hline \multirow[t]{4}{*}{3} & B & 3,3 & 1,99 & 60,30 \\
\hline & C & 3,35 & 3,21 & 95,82 \\
\hline & D & 3,28 & 3,14 & 95,73 \\
\hline & A & 3,04 & 2,41 & 79,28 \\
\hline \multirow[t]{4}{*}{4} & B & 2,91 & 2,16 & 74,23 \\
\hline & C & 2,93 & 2,45 & 83,62 \\
\hline & D & 2,96 & 2,55 & 86,15 \\
\hline & A & 3,72 & 3,53 & 94,89 \\
\hline \multirow[t]{4}{*}{5} & B & 3,78 & 2,62 & 69,31 \\
\hline & C & 3,44 & 3 & 87,21 \\
\hline & D & 3,72 & 3,05 & 81,99 \\
\hline & A & 3,87 & 3,03 & 78,29 \\
\hline \multirow[t]{4}{*}{6} & B & 3,94 & 3,29 & 83,50 \\
\hline & C & 3,91 & 3,49 & 89,26 \\
\hline & D & 3,88 & 2,31 & 59,54 \\
\hline & A & 3,93 & 3,65 & 92,88 \\
\hline \multirow[t]{4}{*}{7} & B & 4,01 & 3,86 & 96,26 \\
\hline & C & 4,01 & 3,76 & 93,77 \\
\hline & D & 3,86 & 2,67 & 69,17 \\
\hline & A & 5,29 & 4,55 & 86,01 \\
\hline \multirow[t]{4}{*}{8} & B & 4,95 & 1,83 & 36,97 \\
\hline & C & 5,34 & 3,25 & 60,86 \\
\hline & D & 5,29 & 3,95 & 74,67 \\
\hline & A & 3,07 & 2,77 & 90,23 \\
\hline \multirow[t]{4}{*}{9} & B & 3,08 & 2,66 & 86,36 \\
\hline & C & 3,21 & 3,21 & 100,00 \\
\hline & D & 3,18 & 3,05 & 95,91 \\
\hline & A & 3,7 & 3,7 & 100,00 \\
\hline \multirow[t]{3}{*}{10} & B & 3,41 & 2,59 & 75,95 \\
\hline & C & 3,26 & 3,21 & 98,47 \\
\hline & D & 3,64 & 3,58 & 98,35 \\
\hline
\end{tabular}


Tabela 09 - Análise Microscópica: medidas dos condutos radiculares

\begin{tabular}{cccc}
\hline Dente & Início & Final & Comprimento \\
\hline $\mathbf{1}$ & 16,825 & 4,207 & 12,618 \\
$\mathbf{2}$ & 12,432 & 2,12 & 10,312 \\
$\mathbf{3}$ & 20,39 & 11,217 & 9,173 \\
$\mathbf{4}$ & 8,788 & 0,431 & 8,357 \\
$\mathbf{5}$ & 14,53 & 4,124 & 10,406 \\
$\mathbf{6}$ & 25,2 & 14,29 & 10,91 \\
$\mathbf{7}$ & 12,142 & 0,906 & 11,236 \\
$\mathbf{8}$ & 15,255 & 0,85 & 14,405 \\
$\mathbf{9}$ & 15,672 & 7,05 & 8,622 \\
$\mathbf{1 0}$ & 16,645 & 6,523 & 10,122 \\
\hline
\end{tabular}


Tabela 10 - Análise microscópica: medidas da extensão do núcleo dentro do canal e a respectiva porcentagem representativa de sua ocupação em relação ao comprimento do canal

\begin{tabular}{|c|c|c|c|c|c|c|}
\hline Dente & Grupo & $\begin{array}{l}\text { Final do } \\
\text { Núcleo }\end{array}$ & $\begin{array}{l}\text { Final do } \\
\text { Preparo }\end{array}$ & $\begin{array}{l}\text { Espaço não } \\
\text { preenchido }\end{array}$ & $\begin{array}{l}\text { Comprimento } \\
\text { do núcleo }\end{array}$ & $\begin{array}{c}\% \text { de } \\
\text { Preenchimento }\end{array}$ \\
\hline & A & 3,314 & 3,314 & 0 & 12,618 & 100,00 \\
\hline \multirow[t]{4}{*}{1} & B & 0,863 & 0,417 & 0,446 & 12,172 & 96,47 \\
\hline & C & 1,3 & 1,3 & 0 & 12,618 & 100,00 \\
\hline & D & 2,045 & 1,494 & 0,551 & 12,067 & 95,63 \\
\hline & A & 1,403 & 1,246 & 0,157 & 10,155 & 98,48 \\
\hline \multirow[t]{3}{*}{2} & B & 3,57 & 2,6 & 0,97 & 9,342 & 90,59 \\
\hline & C & 1,62 & 1,564 & 0,056 & 10,256 & 99,46 \\
\hline & D & 5,566 & 1,676 & 3,89 & 6,422 & 62,28 \\
\hline \multirow{4}{*}{3} & A & 7,903 & 7,873 & 0,03 & 9,143 & 99,67 \\
\hline & B & 11,196 & 7,765 & 3,431 & 5,742 & 62,60 \\
\hline & C & 1,831 & 1,7 & 0,131 & 9,042 & 98,57 \\
\hline & D & 2,37 & 1,6 & 0,74 & 8,433 & 31,93 \\
\hline \multirow{4}{*}{4} & A & 9,473 & 8,43 & 1,043 & 7,314 & 87,52 \\
\hline & B & 9,386 & 8,22 & 1,166 & 7,191 & 86,05 \\
\hline & C & 8,136 & 8,087 & 0,049 & 8,308 & 99,41 \\
\hline & D & 7,468 & 6,579 & 0,889 & 7,468 & 89,36 \\
\hline \multirow{4}{*}{5} & A & 4,033 & 4,018 & 0,015 & 10,391 & 99,86 \\
\hline & B & 3,448 & 0,942 & 2,506 & 7,9 & 75,92 \\
\hline & C & 1,554 & 1,332 & 0,222 & 10,184 & 97,87 \\
\hline & D & 0,968 & 0,87 & 0,098 & 10,308 & 99,06 \\
\hline & A & 7,166 & 6,99 & 0,176 & 10,734 & 98,39 \\
\hline \multirow[t]{4}{*}{6} & B & 2,31 & 1,06 & 1,25 & 9,66 & 88,54 \\
\hline & C & 0,755 & 0,755 & 0 & 10,91 & 100,00 \\
\hline & D & 3,91 & 0,341 & 3,569 & 7,341 & 67,29 \\
\hline & A & 12,519 & 12,42 & 0,099 & 11,137 & 99,12 \\
\hline \multirow[t]{4}{*}{7} & B & 10,595 & 10,34 & 0,255 & 10,981 & 97,73 \\
\hline & C & 5,777 & 5,147 & 0,63 & 10,606 & 94,39 \\
\hline & D & 5,414 & 2,075 & 3,339 & 7,897 & 70,28 \\
\hline & A & 17,972 & 16,94 & 1,032 & 13,373 & 92,84 \\
\hline \multirow[t]{3}{*}{8} & B & 18,59 & 13,164 & 5,426 & 8,979 & 62,33 \\
\hline & C & 17,287 & 12,66 & 4,627 & 9,778 & 67,88 \\
\hline & D & 12,788 & 9,923 & 2,865 & 11,54 & 80,11 \\
\hline \multirow{4}{*}{9} & A & 5,11 & 5,1 & 0,01 & 8,612 & 99,88 \\
\hline & B & 5,574 & 4,582 & 0,992 & 7,63 & 88,49 \\
\hline & C & 4,352 & 4,352 & 0 & 8,622 & 100,00 \\
\hline & D & 3,873 & 3,873 & 0 & 8,622 & 100,00 \\
\hline \multirow{4}{*}{10} & A & 15,32 & 15,32 & 0 & 10,122 & 100,00 \\
\hline & B & 14 & 11,472 & 2,528 & 7,594 & 75,02 \\
\hline & C & 10,09 & 8,85 & 1,24 & 8,882 & 87,75 \\
\hline & D & 6,02 & 5,933 & 0,087 & 10,035 & 99,14 \\
\hline
\end{tabular}




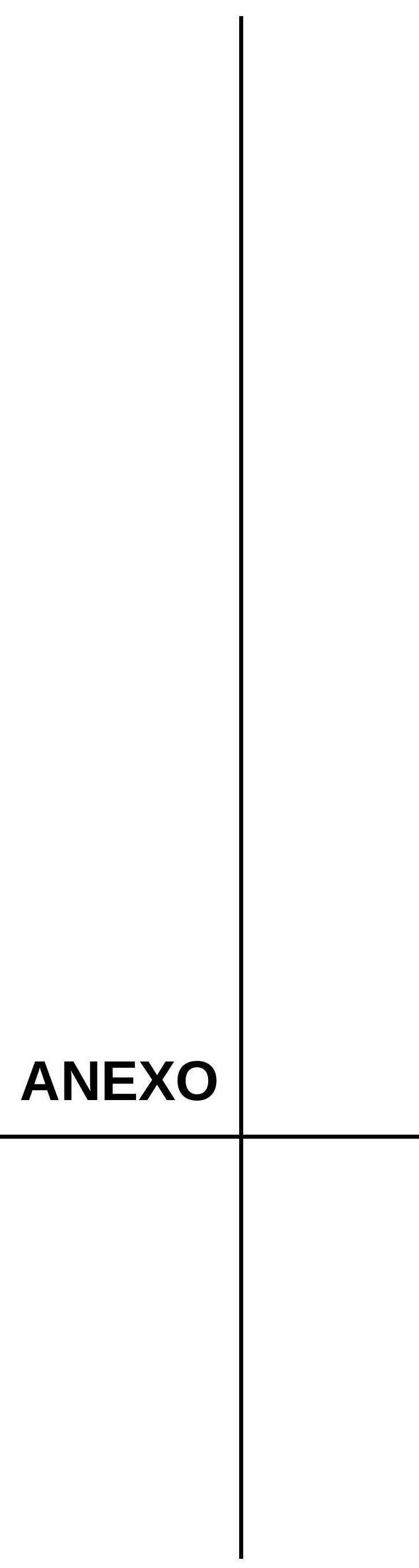




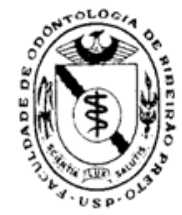

\section{UNIVERSIDADE DE SÃO PAULO FACULDADE DE ODONTOLOGIA DE RIBEIRÃO PRETO COMITÊ DE ÉTICA EM PESQUISA}

Avenida do Café, $s / n^{\circ}$ - Telefone: (016) 3602-3970

14040-904 - Ribeirão Preto - SP - Brasil

Of.CEP/32905/FORP/151205

Fax: (016) 3633-0999

$\mathrm{CAS} /$ cas.

Prezado (a) Professor (a),

\section{Ref. Processo n. 2005.1.1204.58.7}

CAAE n, 0065.0.138.000-05

De ordem do Prof. Dr. Fernando Mandarino - Decano do Comitê de Ética em Pesquisa desta Faculdade informo que o referido Comitê, em sua $63^{a}$ Sessão realizada no dia 13 de Dezembro de 2005, deliberou aprovar o Projeto de Pesquisa envolvendo seres humanos intitulado: "Estudo comparativo de dois materiais de moldagem de conduto radicular para confecção de núcleo metálico fundido", a ser desenvolvido por Vossa Senhoria, na Faculdade de Odontologia de Ribeirão Preto, devendo o atestado para publicação final, ser expedido pelo Comitê de Ética em Pesquisa, após a entrega e aprovação do Relatório Final pelo referido Comitê.

Na oportunidade, solicitamos a gentileza de entregar na Secretaria do Comitê, com o formulário preenchido pelo pesquisador responsável, o Relatório Parcial até o dia $\mathbf{3 0}$ de Agosto de 2006 e o Relatório Final até o dia $\mathbf{3 0}$ Abril de 2007.

Atenciosamente,

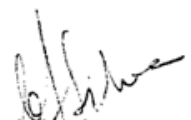

Cândida Adelaide da Silva

Secretária Ad hoc do Comitê de Ética em Pesquisa

II. ${ }^{\text {ma }} \mathrm{Sr},{ }^{\mathrm{a}}$

\section{Prof. ${ }^{a}$ Dr. ${ }^{a}$ Fernanda de Carvalho Panzeri Pires de Souza}

Professor Doutor do Dep. de Materiais Dentários e Prótese - FORP/USP 